\title{
Accounting for cross association in non-self-associating species using a physically consistent SAFT-VR Mie approach
}

\author{
Cripwell, Jamie T.; Kruger, Francois J.; Burger, Andries J.
}

Published in:

Fluid Phase Equilibria

Link to article, DOI:

10.1016/j.fluid.2018.11.003

Publication date:

2019

Document Version

Peer reviewed version

Link back to DTU Orbit

Citation (APA):

Cripwell, J. T., Kruger, F. J., \& Burger, A. J. (2019). Accounting for cross association in non-self-associating species using a physically consistent SAFT-VR Mie approach. Fluid Phase Equilibria, 483, 1-13.

https://doi.org/10.1016/j.fluid.2018.11.003

\section{General rights}

Copyright and moral rights for the publications made accessible in the public portal are retained by the authors and/or other copyright owners and it is a condition of accessing publications that users recognise and abide by the legal requirements associated with these rights.

- Users may download and print one copy of any publication from the public portal for the purpose of private study or research.

- You may not further distribute the material or use it for any profit-making activity or commercial gain

- You may freely distribute the URL identifying the publication in the public portal 


\section{Accepted Manuscript}

Accounting for cross association in non-self-associating species using a physically consistent SAFT-VR Mie approach

Jamie T. Cripwell, Francois J. Kruger, Andries J. Burger

PII:

S0378-3812(18)30456-4

DOI:

Reference: FLUID 11990

To appear in: Fluid Phase Equilibria

Received Date: 30 May 2018

Revised Date: 2 October 2018

Accepted Date: 3 November 2018

Please cite this article as: J.T. Cripwell, F.J. Kruger, A.J. Burger, Accounting for cross association in non-self-associating species using a physically consistent SAFT-VR Mie approach, Fluid Phase Equilibria (2018), doi: https://doi.org/10.1016/j.fluid.2018.11.003.

This is a PDF file of an unedited manuscript that has been accepted for publication. As a service to our customers we are providing this early version of the manuscript. The manuscript will undergo copyediting, typesetting, and review of the resulting proof before it is published in its final form. Please note that during the production process errors may be discovered which could affect the content, and all legal disclaimers that apply to the journal pertain. 
Accounting for cross association in non-self-associating species using a physically consistent SAFTVR Mie approach

Jamie T. Cripwell ${ }^{a}$, Francois J. Kruger ${ }^{a, b}$ and Andries J. Burger ${ }^{a *}$

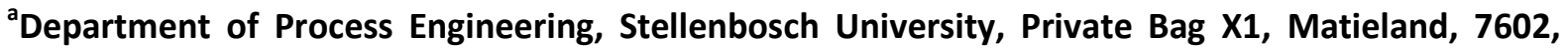
South Africa

${ }^{\mathrm{b}}$ Currently at Center for Energy Resources Engineering (CERE), Department of Chemical and Biochemical Engineering, Technical University of Denmark, 2800 Kgs. Lyngby, Denmark

e-mail: ajburger@sun.ac.za

Abstract

This work presents a formalised, physically consistent approach to account for cross association in the SAFT framework. The focus of the approach was to account for solvation of non-self-associating components, using members of the ketone and ether functional groups as model components. Physical consistency is captured by only considering a single negative site in these components, with the association mechanisms termed the "N scheme" as a result. An accurate polar parameter set is a prerequisite for the approach, where polar and dispersion interactions are already accounted for in pure component properties and those of mixtures where solvation is absent. Using SAFT-VR Mie-GV as the example framework, the approach considers the discretisation of the two association parameters, and it applies the resulting matrix of parameter sets to mixture VLE data for the ketone or ether with alcohols in the $C_{2}$ to $C_{4}$ range. Analysis of the resulting $A A D$ contour plots demonstrate that the use of average solvation parameters for each functional groups are appropriate, rather than component-specific parameters, and they offer excellent pure predictions for alcohol mixtures and good predictions for aqueous mixtures. As a final test, the approach was applied to chloroform, considering a single positive site and using the proposed parameterisation method. The resulting "P scheme" for chloroform, in conjunction with the $\mathrm{N}$ scheme for acetone, yields excellent predictions for the quintessential chloroform/acetone mixture and emphasises the suitability and predictive strength of the approach.

Keywords: cross association; solvation; hydrogen bonding; SAFT-VR Mie; polar SAFT; polar; vapourliquid equilibria; ketone; ether; chloroform

1. Introduction 
Molecular association is an umbrella term that collectively describes the anisotropic intermolecular forces that result in the formation of dimers and higher order complexes. Association between like (similar) molecules is frequently referred to as self-association, while complex formation involving unlike (dissimilar) components is termed cross-association or solvation. While all components that self-associate have the ability to solvate as well, not all components that can solvate necessarily exhibit self-association. The distinction is made by considering the chemical nature of the component - specifically the presence of proton donor and acceptor sites that participate in association. Vinogradov and Linnell [1] provide an excellent classification scheme for association behaviour. They distinguish between components with: proton donor sites only (Type I), proton acceptor sites only (Type II), both donor and acceptor sites (Type III) and components with neither (Type IV). By this definition, Type III components include all self-associating species where both self-association and solvation are possible. Type I and Type II species on the other hand, while unable to self-associate, are able to solvate with Type III components and indeed also with each other.

The electrostatic forces of association are typically an order of magnitude larger than strong molecular dipoles, and two to three orders stronger than the London dispersion forces common to all chemical species [2]. It is for this reason that molecular association tends to govern the thermodynamic behaviour of species capable of forming these complexes, and require explicit consideration by thermodynamic models to account for resulting non-ideal behaviour. The ability to account for molecular association is arguably the key feature responsible for the rapid development of the Statistical Associating Fluid Theory (SAFT). The fact that the original association term in SAFT-0 $[3,4]$ has remained largely unchanged, despite the extensive development of the monomer and chain terms by subsequent SAFT variants, is testament to the revolutionary nature of Wertheim's seminal works [5-8] more than 30 years ago. This thermodynamic perturbation theory of first order (TPT1) has been used extensively to describe the thermodynamic behaviour of archetypal hydrogen bonding molecules, including water, alcohols and organic acids in every SAFT variant since SAFT-0. A significant qualification of this modelling success however, is that all of these hydrogen bonding species are strictly Type III components. The so-called "induced association" [9] of Type I and II components has received far less attention and remains an open ended problem in the literature.

In this work, we endeavour to approach the problem of solvation (cross-association) by using a general and physically consistent approach, thereby establishing predictive applicability for a wide range of components. We begin by considering the previous attempts at accounting for cross- 
association of non-associating species, identifying the strengths and flaws of each, to arrive at a formalised approach.

\section{Accounting for Association in SAFT}

The first step to accounting for association in SAFT is the definition of association mechanisms; this is achieved through selection of an association scheme for the component in question. An association scheme indicates the number of active proton donor and acceptor sites on each molecule, and thus the mechanisms for possible site-site interactions between molecules.

\subsection{Traditional Approaches}

Huang and Radosz $[10,11]$ defined a number of association schemes in their foundational $\mathrm{SAFT}_{\mathrm{HR}}$ works, which were based on the atomic structure of self-associating (Type III) functional groups, some of which are presented in Table 1. The 3B scheme for example accounts for the two proton donor and single proton acceptor sites present on the hydroxyl functional group of alcohols, while the $4 \mathrm{C}$ scheme was explicitly developed to represent the extensive hydrogen bonding structures of water through its two lone electron pairs and two polarised hydrogen atoms.

The 3B and $4 \mathrm{C}$ schemes were referred to as "rigorous" in the works of Huang and Radosz [10] as they are exhaustive; accounting for all possible sites of molecular association. However, these rigorous schemes do not account for the limiting effects of steric hindrance, where chain length and molecular structures (rings, branches, etc.) limit the degree of association in heavier molecules. To accounting for these physical limitations in related predictive models, one needs to make simplifying assumptions regarding the activity of different sites. Reconsidering the alkanolic hydroxyl group as an example, such a simplification is evident in the definition of the $2 \mathrm{~B}$ scheme. Here, two different (proton acceptor) sites are combined into a single active site, which is said to participate in hydrogen bond formation. This simplification more accurately represents the degree of association in alcohols larger than methanol, which explains its widespread use in the SAFT literature. 
Table 1: Association schemes traditionally applied to different functional groups in the literature

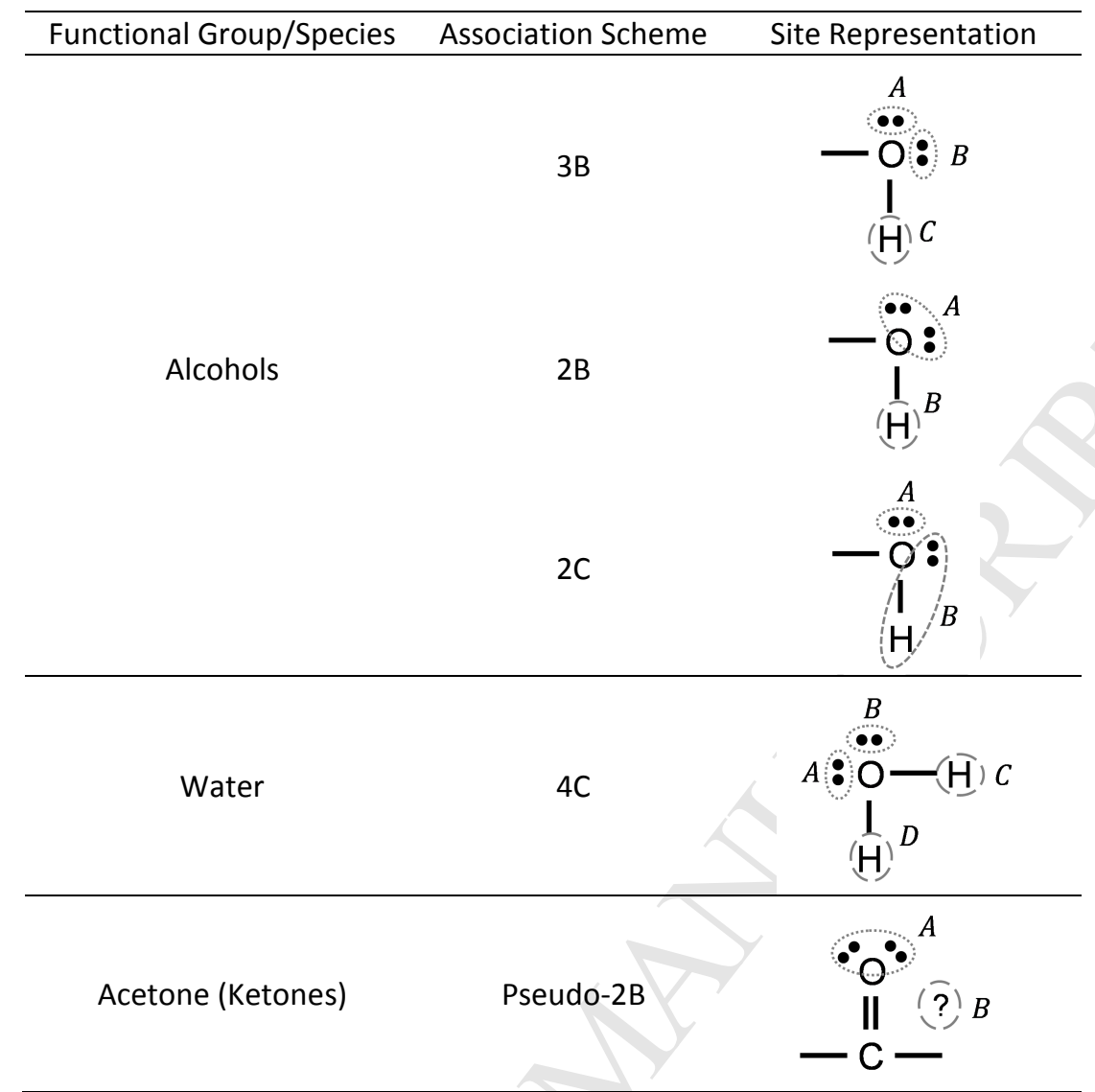

This physical consideration is central to an analysis of previous attempts to model solvation in Type I and II components, where one of the earliest and most prevalent approaches is to consider these components as "pseudo self-associating" [12]. Accordingly, using acetone as a model component, the Type II behaviour is modelled by applying the $2 \mathrm{~B}$ association scheme. The underlying assumption of this approach is clear when one analyses the structure of the acetone carboxyl group in Table 1, but the need for this assumption needs to be contextualised by considering the parameterisation of SAFT. The standard regression procedure (SRP) employs an objective function considering pure component properties alone. In the case of Type III components, the significant influence of self-association on pure fluid behaviour is captured in the magnitude of the appropriate association energy $\left(\varepsilon^{A B} / k\right)$ and volume (e.g. $\left.k^{A B}\right)$ parameters. However, due to the physical nature of Type I and II components, their association sites are effectively dormant in the pure state.

The pseudo-association approach thus essentially relaxes the rigorous physical description of the component to allow for the determination of association parameters from pure component data. The resulting parameter sets yield vastly improved predictions of solvation compared to the case where cross-association is ignored. Subsequent work in both the SAFT $[9,13]$ and Cubic Plus 
Association (CPA) [14] frameworks have investigated the influence of different mixing rules (CR1, ECR [15] and that of Wolbach \& Sandler [16]) and the fixing of association parameter values to improve model performance. Despite the "rigorous physical meaning of this approach" being called into question [13], these studies have worked within the assumption, sticking to the boundaries of the traditional association schemes, rather than investigating more physically rigorous alternatives.

Theoretically, the association schemes formally define the strength (explicitly, $\Delta^{A i B j}$ ) and prevalence (implicitly, $X_{A i}$ ) of all possible interactions between different sites on different components. Algebraically, they allow for the explicit calculation of $X_{A i}$ from its general implicit form in Equation 1, by defining the relationship between $X_{A i}$ and $X_{B j}$ for all components and all site types.

$$
X^{A_{i}}=\left[1+N_{A} \sum_{i} \sum_{B_{j}} \rho_{j} X^{B_{j}} \Delta^{A_{i} B_{j}}\right]^{-1}
$$

Analytical solutions to this "mass-action" equation were necessary, not only for explicit calculation of the association contribution, but for the calculation of thermodynamic derivatives of the Helmholtz energy expansion at SAFT's core. This necessity entrenched the SAFT $\mathrm{HR}_{\text {association }}$ scheme terminology in all subsequent development of the framework, but it also "inhibit[ed] creative applications and hypotheses... because of the time-consuming effort of rederiving and recoding the specific versions of [Equation 1] and its derivatives" [17] and explains, at least in part, why researchers worked within these limitations. More recently however, innovative solutions such as Michelsen et al.'s Q-Function [18,19] or the method proposed by Tan et al. [20] have removed these limitations by allowing for more rapid computation without the need for coding analytical solutions. These developments provide the impetus and the tools to explore a more physically representative treatment of solvating Type I and II components.

\subsection{Modified Approaches for Solvation}

Physically consistent approaches have been used in select applications of the CPA [21], GCA [22], GC-SAFT $[23,24]$, PC-SAFT $[25,26]$ and SAFT- $\psi$-Mie [27] equations of state, where a range of Type II components have been successfully modelled by considering proton acceptor sites only. However, closer inspection of such modelling strategies reveals a number of inconsistencies, with no consensus on a formal treatment of these components.

The first discrepancy arises over the treatment of molecular dipoles: while the GC-SAFT $[23,24]$ and PC-SAFT $[25,26]$ approaches account for dipolar interactions, the SAFT- $\nu$-Mie approach 
of Sadeqzadeh et al. [27] omits an explicit polar term. Instead, they considered acetone to have both a proton donor and a proton acceptor site in the pure component form, with an additional proton acceptor site being "activated" in appropriate mixtures. This is, in essence, identical to the pseudo self-associating treatment: the dipolar effects are assimilated into the association contribution, with the Type II solvation behaviour captured in the switch from $2 \mathrm{~B}$ to $3 \mathrm{~B}$ treatment for mixtures. Unfortunately, such a treatment provided only qualitative predictions of mixture behaviour, particularly in mixtures with non-associating components - a result which contributes to an extensive body of SAFT literature highlighting the need to explicitly account for dipolar interactions [28-32].

Among the cases where dipolar interactions were explicitly accounted for, there is inconsistency in the parameterisation procedure. Following the group contribution approach, Nguyen-Huynh et al. $[23,24]$ proposed that the association energy and volume parameters of the ketone, ester and ether functional groups be fixed to those of the 1-alcohol functional group, using a single proton acceptor site for all three functional groups. This simple approach yielded fair results for all three functional groups in mixtures with 1-alcohols, but the predictive strength of the approach is unclear, given that other associating components (e.g. secondary alcohols, water) were not considered. Moreover, how the approach would be extended to Type 1/Type II mixtures is entirely unaddressed. The more traditional regression approach was recently employed by Corazza et al. $[25,26]$ in a very specific application to long chain esters relevant to the biofuels industry. Considering the esters to have two proton acceptor sites, the authors regressed the association parameters of ethyl acetate using an objective function considering binary VLE data with methanol, ethanol, isopropanol and $\mathrm{n}$-butanol. Assuming transferability, these association parameters were used for the larger esters of practical interest to the study. The non-associating PC-SAFT parameters (viz. $\sigma, m$ and $\varepsilon / k$ ) were determined using the traditional SRP approach, with the Jog \& Chapman (JC) polar parameter [28,33] fixed using an empirical procedure proposed by Dominik et al. [34]. Following this regression strategy, excellent pure predictions were obtained for ester/ester and ester/1-alcohol mixtures. However, neither different Type II components, nor different mixture types (viz. aqueous, Type I/Type II) were considered in this application-specific case.

When one reviews the current literature related to the modelling of solvation in the SAFT framework, a prominent characteristic is the lack of a formalised, general procedure to account for such cross association. While the aforementioned cases provide either general or predictive strategies to tackle this problem, the inconsistencies between the approaches leave ample room for systematic improvement. Specifically, an approach that is both predictive and that can be used for 
different Type I and II solvating components has yet to be formally proposed. This is the overarching aim of our current work: a comprehensive regression strategy for parameterising Type I and II components to yield predictive results in the SAFT framework.

3. The $\mathrm{N}$ scheme Approach

We begin our approach by considering the structure of the functional groups under consideration. In this preliminary work, we look to define a general approach for the members of the ketone and ether functional groups, where the lone electron pairs of the oxygen atom in the ketone's branch, or in the ether's backbone, constitute two potential sites for solvation. Thus, the first consideration in our formalised approach is whether to incorporate a rigorous two-site mechanism, or to consider a simplified one-site approach. To this end, we reassess similar arguments for the $3 \mathrm{~B}$ and $2 \mathrm{~B}$ association schemes for alcohols, and recall the steric hindrance arguments favouring the use of the simplified $2 \mathrm{~B}$ scheme. Considering the smallest ketone and ether sizes (i.e. $C_{3}$ and equivalent), as well as the central location of these functional groups, the steric hindrance argument is even more pertinent for these components than for primary alcohols. Moreover, Nguyen-Huynh et al. [23] conducted a preliminary analysis on the optimal number of solvation sites in Type II components, concluding that the rigorous treatment tends to over-predict the degree of solvation. Thus, we combine the lone electron pairs on the oxygen atom to form a single proton acceptor site as illustrated in Table 2. The moniker "N scheme" [35] is adopted to reflect the single "negative" site used in the solvation mechanism.

Table 2: The proposed $N$ scheme applied to ketone and ether functional groups

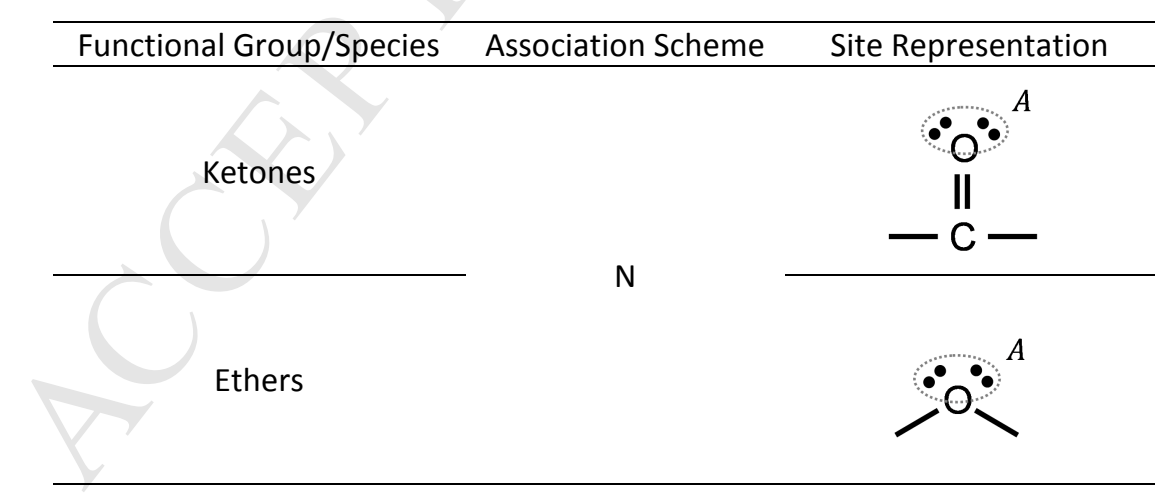

\subsection{Parameters \& Mixture Data}

The aim of the $\mathrm{N}$ scheme is to develop a predictive SAFT approach that accounts for crossassociation. However, accurately accounting for the effects of solvation should not affect the predictive capacity of the SAFT model to account for component behaviour in non-solvating systems. Rather, the $\mathrm{N}$ scheme should supplement a predictive SAFT approach with only the association 
parameters requiring fitting. To this end, we use the recently developed SAFT-VR Mie-GV [32] equation of state in this work, but we will also demonstrate that the approach is readily extended to other SAFT variants.

SAFT-VR Mie-GV incorporates the Gross \& Vrabec (GV) dipolar term [30] into the SAFT-VR Mie framework [36]. For polar, non-self-associating species, the model considers the traditional segment diameter $(\sigma)$, segment number $(m)$ and dispersion energy $(\varepsilon / k)$, the Mie potential's repulsive range exponent $\left(\lambda_{\mathrm{r}}\right)$ as well as the number of polar segments $\left(n_{p}\right)$ - the GV polar parameter. A more comprehensive summary is provided in the Supporting Information. In our previous work on polar species [32], we presented a regression strategy for SAFT-VR Mie-GV dependent on pure component properties alone. The resulting parameters exhibited excellent predictive capacity for both pure component properties and those of polar/nonpolar and polar/polar mixtures. This fixed polar parameter (FPP) approach fixes the value of $\left(n_{p}\right)$ using homologous group specific correlations, with the nonpolar parameters regressed by using pure component properties in the traditional SRP approach. The work also highlighted the robustness and predictive capacity of the GV polar term compared to its JC counterpart - a point of significance given that both the GC-SAFT of Nguyen-Huynh et al. $[23,24]$ and polar PC-SAFT of Corazza et al. $[25,26]$ used the latter in their solvation approaches.

In accordance with our aim of developing a truly predictive approach, we use the previously determined SAFT-VR Mie-GV parameter sets for ketones and ethers as the foundation for the current work. Using this basis, only the solvation parameters require fitting. The five non-solvation parameters are fixed to those values determined using the FPP approach, as listed in Table 3. As the reproduced \%AADs suggest, these parameter sets capture the pure component properties with a high degree of accuracy and serve as an excellent starting point for the development of a fundamental solvation contribution. The reader is referred to our previous work for a more detailed discussion of the performance of these parameter sets to non-solvating systems.

In the SAFT-VR Mie framework, the energy $\left(\varepsilon^{A B} / k\right)$ and range of association $\left(r_{c}^{A B}\right)$ are used to account for molecular association, or equivalently solvation in the context of this work. The latter term is the point of departure from traditional SAFT approaches, where the association volume $\left(\kappa^{A B}\right)$ is usually considered. The SAFT-VR Mie approach considers a temperature dependent association volume by redefining the quantity as a function of the temperature dependent segment diameter $(d)$ according to equation 2 . Here the $r_{d}^{A B}$ term defines the distance between the associating site and its corresponding segment centre and is fixed to a value of $0.4 \sigma$, while $r_{c}^{A B}$ (parameterised as the dimensionless ratio $r_{c}^{A B} / \sigma$ ) is the regressed parameter. 


$$
\begin{aligned}
\kappa^{A B}= & \frac{4 \pi d^{2}}{72\left(r_{d}^{A B}\right)^{2} \sigma^{3}}\left[\ln \left(\frac{r_{c}^{A B}+2 r_{d}^{A B}}{d}\right)\left(6\left(r_{c}^{A B}\right)^{3}+18\left(r_{c}^{A B}\right)^{2} r_{d}^{A B}-24\left(r_{d}^{A B}\right)^{3}\right)+\right. \\
& \left.\left(r_{c}^{A B}+2 r_{d}^{A B}-d\right)\left(22\left(r_{d}^{A B}\right)^{2}-5 r_{c}^{A B} r_{d}^{A B}-7 r_{d}^{A B}-8\left(r_{c}^{A B}\right)^{2}+r_{c}^{A B} d+d^{2}\right)\right]
\end{aligned}
$$

Table 3: Non-associating SAFT-VR Mie-GV parameters regressed using the FPP approach for ketones and ethers

\begin{tabular}{|c|c|c|c|c|c|c|c|c|c|c|c|c|}
\hline & $\begin{array}{c}M_{W} \\
\text { g.mol }{ }^{-1}\end{array}$ & $\begin{array}{l}\sigma \\
\AA\end{array}$ & $m$ & $\begin{array}{c}\varepsilon / k \\
\mathrm{~K}\end{array}$ & $\lambda_{a}$ & $\lambda_{r}$ & $n_{p}$ & $\begin{array}{l}\mu \\
D\end{array}$ & $\begin{array}{c}P^{\text {sat * }} \\
\text { AAD\% }\end{array}$ & $\begin{array}{c}\rho^{\text {sat * }} \\
\text { AAD\% }\end{array}$ & $\begin{array}{l}u^{\text {liq }} t \\
\text { AAD\% }\end{array}$ & $\begin{array}{c}H^{\text {vap * }} \\
\text { AAD\% }\end{array}$ \\
\hline \multicolumn{13}{|l|}{ Ketones } \\
\hline acetone & 58.08 & 3.4290 & 2.4452 & 240.214 & 6 & 11.6448 & 1.1651 & 2.88 & 0.287 & 0.273 & 7.71 [37] & 1.318 \\
\hline 2-butanone & 72.11 & 3.6138 & 2.6027 & 257.887 & 6 & 11.9565 & 1.4308 & 2.76 & 0.462 & 0.149 & $3.50[38,39]$ & 1.260 \\
\hline 2-pentanone & 86.13 & 3.8842 & 2.5546 & 309.096 & 6 & 14.2015 & 1.5814 & 2.77 & 0.121 & 0.368 & 4.04 [39] & 2.698 \\
\hline 3-pentanone & 86.13 & 4.0097 & 2.3494 & 342.831 & 6 & 16.1235 & 1.5258 & 2.82 & 1.000 & 0.036 & $-{ }^{a}$ & 2.703 \\
\hline 2-heptanone & 114.1 & 4.0856 & 2.9591 & 331.839 & 6 & 14.4697 & 2.1428 & 2.61 & 0.302 & 0.052 & $1.44[39,40]$ & 1.854 \\
\hline 3-heptanone & 114.1 & 3.9978 & 3.0839 & 325.042 & 6 & 14.6525 & 1.8486 & 2.81 & 0.766 & 0.924 & $-{ }^{a}$ & 2.215 \\
\hline 4-heptanone & 114.1 & 4.3515 & 2.5258 & 390.102 & 6 & 18.0162 & 2.0323 & 2.68 & 0.307 & 0.069 & $-{ }^{a}$ & 1.023 \\
\hline \multicolumn{13}{|l|}{ Ethers } \\
\hline diethyl ether & 74.12 & 3.7181 & 2.5763 & 237.444 & 6 & 12.0503 & 3.6616 & 1.15 & 0.408 & 0.633 & $-{ }^{a}$ & 1.695 \\
\hline di-n-propyl ether & 102.18 & 4.3646 & 2.3167 & 357.437 & 6 & 17.3943 & 3.5238 & 1.21 & 0.147 & 0.538 & $--^{a}$ & 1.026 \\
\hline butyl ethyl ether & 102.18 & 4.2600 & 2.4820 & 349.730 & 6 & 17.6002 & 3.4662 & 1.22 & 1.082 & 0.658 & $-{ }^{a}$ & 7.597 \\
\hline dibutyl ether & 130.23 & 4.3581 & 2.9326 & 363.107 & 6 & 17.4657 & 4.3989 & 1.17 & 0.572 & 0.646 & $-^{a}$ & 1.464 \\
\hline
\end{tabular}
[32]

*\%AADs with reference to appropriate DIPPR Correlations [41]

$+\% A A D s$ in $u^{l i q}$ calculated with reference to data sets as individually referenced

${ }^{a}$ No \%AADs possible due to lack of published data

The nature of Type II solvation dictates that these association parameters be fit to data of mixtures where such cross association is evident. An important consideration is thus the choice of second component in the mixture. To this end, we elect to follow a similar strategy to Corazza et al. [25] by considering mixtures with each linear chain alcohol in the $C_{2}$ to $C_{4}$ range. By considering both primary and secondary alcohols in this range, we hope to account for the effects of both molecular size and hydroxyl group location on the resulting association behaviour. In order to generate accurate association parameters for the ketones and ethers, reliable parameter sets for the alcohols have to be used. The SAFT-VR Mie-GV alcohol parameters used in this work were shown to yield accurate predictions for alcohol/n-alkane and alcohol/water mixtures [42], and are listed in Table S1 and S2 of the Supporting Information. Unlike the work of Corazza et al. [25] however, we consider the results for all ketone/alcohol and ether/alcohol mixtures rather than just that of a model component. In this way, we hope to identify systematic trends for the functional groups with changing molecular weights and functional group locations. Thus, we consider all the available literature data compiled in Table 4. 
Table 4: Alcohol mixture data considered for regression of association parameters for ketones and ethers

\begin{tabular}{c|ccccc} 
& ethanol & 1-propanol & 2-propanol & 1-butanol & 2-butanol \\
\hline acetone & {$[43]$} & {$[44]$} & {$[45]$} & {$[46]$} & {$[47]$} \\
2-butanone & {$[48]$} & {$[48]$} & {$[48]$} & {$[49]$} & {$[49]$} \\
2-pentanone & {$[50]$} & - & {$[51]$} & {$[52]$} & - \\
3-pentanone & {$[53]$} & - & {$[54]$} & {$[55]$} & - \\
diethyl ether & {$[53]$} & - & - & - & - \\
di-n-propyl ether & {$[53]$} & {$[56]$} & {$[57]$} & - & - \\
dibutyl ether & {$[58]$} & - & - & {$[56]$} & {$[59]$} \\
\hline
\end{tabular}

\subsection{Discretised Regression}

The final step in the regression strategy is traditionally the development of an appropriate objective function and the selection of a minimisation algorithm to yield the optimal parameter set. However, given that only two parameters require fitting, we are presented with a unique opportunity to systematically investigate the effect of varying association parameter values on the resulting prediction quality. Specifically, we propose the use of a discretised regression approach for this purpose. Discretised regression considers two linked parameters ( $\alpha$ and 6 ), defining physically significant upper and lower bounds for the parameters, and dividing the resulting range $\left[\alpha / B_{\min }: \alpha / B_{\max }\right]$ into $n$ discrete intervals. Each parameter combination $\left(\alpha_{n} ; B_{n}\right)$ is considered fixed, with the remaining parameters regressed in the traditional manner. The result is a grid of minimised objective functions, linked to the discrete values of the $\alpha$ and $B$ parameters, which can be projected onto a contour plot. In this way, the resulting parameter space can be visualised, allowing not only for the avoidance of numerical pitfalls, but also for theoretical considerations to be made in parameter determination. The latter is key when considering physically significant parameters like those in the SAFT framework, as it allows for some relaxation of the strict mathematical rigour of numerical techniques. The approach was first used in the SAFT-VR Mie framework by Clark et al. [60], who discretised $\varepsilon / k$ and $\varepsilon^{A B} / k$ in order to distinguish the relative contributions of the dispersion and association energies to the overall system behaviour of alcohols.

In the context of this work, the association parameters are certainly linked, and so we can consider physically significant bounds for $\varepsilon^{A B} / k$ and $r_{c}^{A B} / \sigma$. For the ketone and ether solvation parameters, we define the bounds as $\varepsilon^{A B} / k \in[1500 ; 3000]$ and $r_{c}^{A B} / \sigma \in[0.28 ; 0.46]$, considering 30 intervals in each parameter. These bounds are based on regressed parameter sets for selfassociating species $[36,42,61]$. By discretising the association parameters and using the previously determined non-associating parameter sets, no parameters require fitting. Thus, instead of minimising an objective function, we can consider model predictions for mixture VLE at each 
$\left[\varepsilon^{A B} / k ; r_{c}^{A B} / \sigma\right]$ combination, using the absolute average deviations (AAD) in $y$ and $T$, or \%AADs in $P$, to construct the appropriate contour plots. By considering these surfaces for each of the considered ketones and ethers, we can gain a more intuitive understanding of the solvation behaviour of the functional groups as a whole.

4. Results

\subsection{Discretisation Results}

The discretised regression procedure was applied to each ketone/alcohol and ether/alcohol mixture for which literature data were available, as presented in Table 4. The polar species were modelled using the proposed $\mathrm{N}$ scheme, while the alcohols were modelled using both the $2 \mathrm{~B}$ and $2 \mathrm{C}$ association schemes. Both schemes were considered for the alcohols, since they provided comparable predictions for both aqueous and nonpolar mixtures, with no clear predictive superiority between them. Thus, until a clear distinction can be drawn between their predictive capacities, we will endeavour to develop the model infrastructure using both schemes.

The results of the discretised regression provided some significant insights when considering the respective homologous groups, as typified by the AAD contour plots for the acetone/ethanol and 3-pentanone/1-butanol mixtures, using the $2 \mathrm{~B}$ association scheme for the alcohols (Figure 1). These two cases are chosen because they cover opposite ends of the considered spectrum in terms of molecular weights of the ketones and alcohols under consideration, but the same trends hold for all other considered cases. The first notable feature is the common shape of the contours, where there is a clear inverse relationship between $\varepsilon^{A B} / k$ and $r_{c}^{A B} / \sigma$. While this interplay is dictated by the theoretical relationship between the parameters in the association term, what is not immediately apparent from inspection of the theory is the expected magnitudes of the parameters, and indeed the location of the minima. Figure 1 demonstrates that, regardless of the molecular weight of the alcohol and ketone in question, the nature of the ketone solvation is the same - specifically, the valley of minimum $\left[\varepsilon^{A B} / k ; r_{c}^{A B} / \sigma\right]$ combinations is identical for all members of the ketone functional group. 

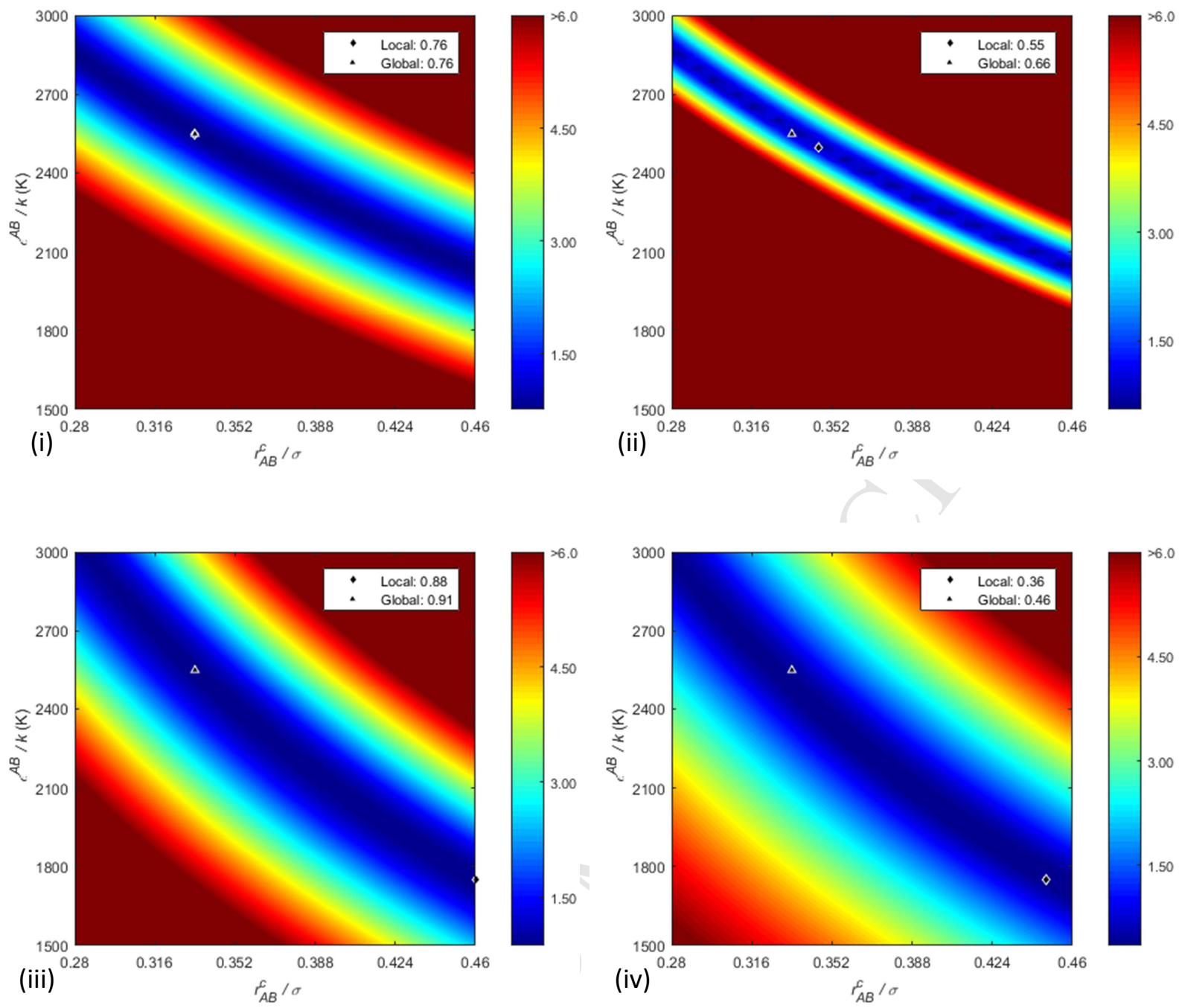

Figure 1: Contour plots illustrating the discretised regression results for two ketone $(N) /$ alcohol I(2B) mixtures: (i) $A A D y$ \& (ii) \%AADP for acetone/ethanol at $313.15 \mathrm{~K}$ [43]; and (iii) AADy \& (iv) AADT for 3-pentanone/1butanol at 1.013 bar [55]

The same trends are evident for the ether/alcohol mixtures in Figure 2, although the inverse relationship is clearly shifted towards lower values for the association energy compared to the ketone/alcohol mixture equivalents. Such a trend makes physical sense, with the more sterically hindered ether functional group forming weaker hydrogen bonds than the more exposed ketone carboxyl groups. 

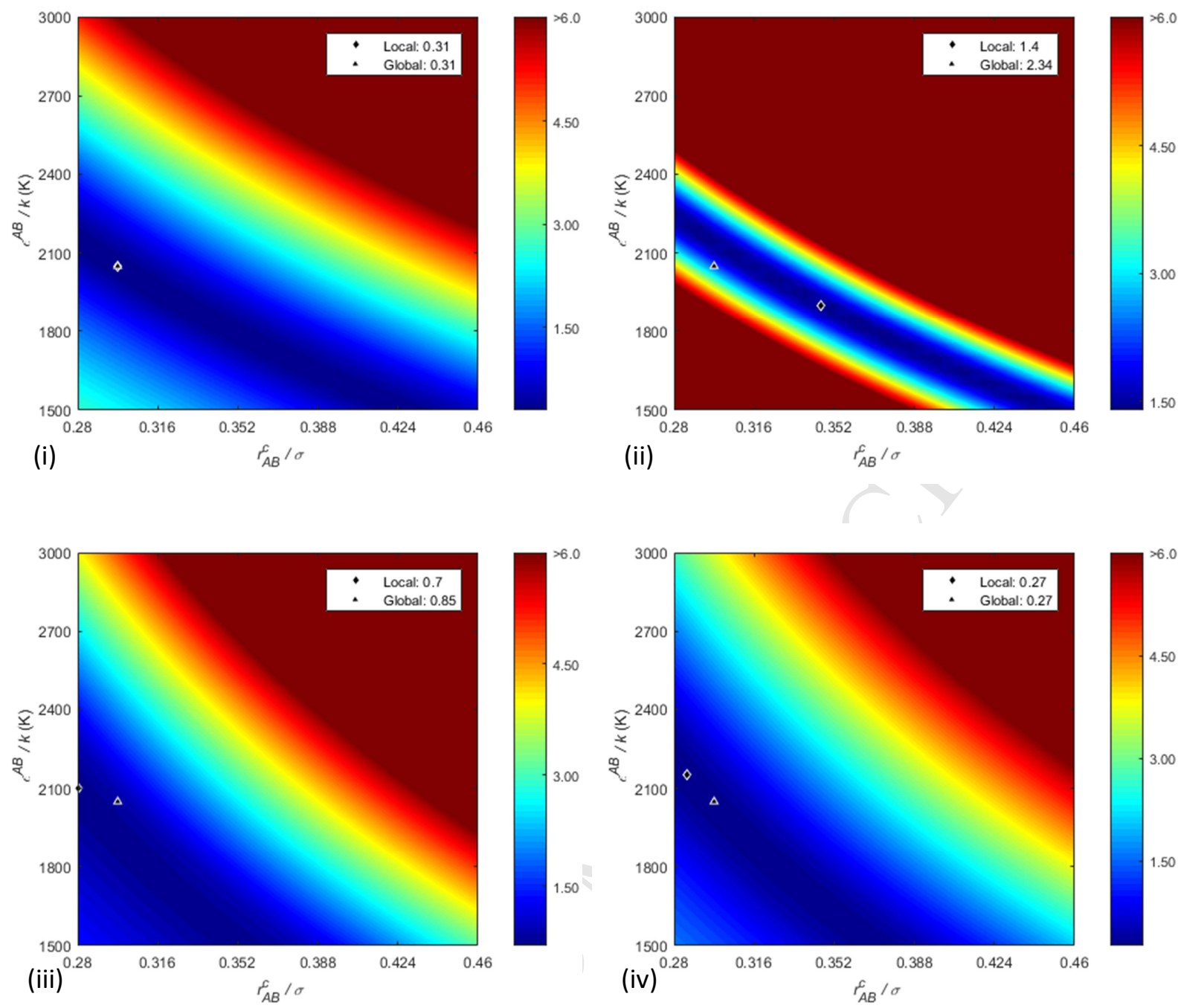

Figure 2: Contour plots illustrating the discretised regression results for two ether ( $N) /$ alcohol (2B) mixtures: (i) $A A D y$ \& (ii) \%AADP for diethyl ether/ethanol at $313.15 \mathrm{~K}$ [33]; and (iii) AADy \& (iv) AADT for dibutyl ether/1butanol at 1.013 bar [56]

The significance of these results can be appreciated if one considers the results that would have been obtained via standard regression, i.e. the local minima in Figures 1 and 2. Considering the ketones as an example again, the local minimum for the acetone/ethanol mixture $\left(\varepsilon^{A B} / \mathrm{k}=2550 \mathrm{~K}\right.$, $\left.r_{c}^{A B} / \sigma=0.334\right)$ is far removed from the 3-pentanone/1-butanol minimum $\left(\varepsilon^{A B} / k=1750 K, r_{c}^{A B} / \sigma=\right.$ 0.46), but the contour plots show that the difference in resulting AAD values is almost negligible. The summary of local minima AADs for all considered systems in Table 5 shows this trend to be true for all components considered in the discretised approach. 
ACCEPTED MANUSCRIPT

Table 5: Summary of local minima AADs for discretised approach applied to ketone and ethers

\begin{tabular}{|c|c|c|c|c|c|c|c|c|c|}
\hline Component & Mixture & $\varepsilon^{A B} / k(K)$ & $r_{c}^{A B} / \sigma$ & AADy & $\begin{array}{l}\text { AADT (K) } \\
/ \% A A D P\end{array}$ & $\varepsilon^{A B} / k(K)$ & $r_{c}^{A B} / \sigma$ & AADy & $\begin{array}{l}\text { AADT (K) } \\
/ \% A A D P\end{array}$ \\
\hline \multicolumn{10}{|l|}{ Ketones } \\
\hline \multirow{5}{*}{ acetone } & ethanol & 2650 & 0.316 & 0.76 & $0.55 \%$ & 2550 & 0.382 & 1.36 & $2.95 \%$ \\
\hline & 1-propanol & 2000 & 0.460 & 0.82 & $0.58 \mathrm{~K}$ & 2250 & 0.46 & 1.61 & $1.20 \mathrm{~K}$ \\
\hline & 2-propanol & 1750 & 0.460 & 1.51 & $0.37 \mathrm{~K}$ & 1900 & 0.454 & 2.80 & $0.77 \mathrm{~K}$ \\
\hline & 1-butanol & 1900 & 0.418 & 0.39 & $0.75 \mathrm{~K}$ & 1950 & 0.454 & 0.46 & $1.06 \mathrm{~K}$ \\
\hline & 2-butanol & 2150 & 0.412 & 1.07 & $1.95 \%$ & 2400 & 0.388 & 1.34 & $2.26 \%$ \\
\hline \multirow[t]{5}{*}{ 2-butanone } & ethanol & 2550 & 0.340 & 0.54 & $0.16 \mathrm{~K}$ & 3000 & 0.304 & 1.05 & $0.30 \mathrm{~K}$ \\
\hline & 1-propanol & 1900 & 0.460 & 0.55 & $0.16 \mathrm{~K}$ & 2100 & 0.454 & 1.32 & $0.40 \mathrm{~K}$ \\
\hline & 2-propanol & 2050 & 0.412 & 0.62 & $0.19 \mathrm{~K}$ & 1950 & 0.460 & 1.26 & $0.41 \mathrm{~K}$ \\
\hline & 1-butanol & 1950 & 0.454 & 1.55 & $0.53 \mathrm{~K}$ & 2250 & 0.448 & 1.45 & $0.81 \mathrm{~K}$ \\
\hline & 2-butanol & 1850 & 0.460 & 1.06 & $0.48 \mathrm{~K}$ & 1950 & 0.454 & 1.35 & $0.60 \mathrm{~K}$ \\
\hline \multirow[t]{3}{*}{ 2-pentanone } & ethanol & 1850 & 0.460 & 1.04 & $1.33 \mathrm{~K}$ & 3000 & 0.292 & 1.54 & $1.63 \mathrm{~K}$ \\
\hline & 2-propanol & 3000 & 0.280 & 0.92 & $0.37 \mathrm{~K}$ & 3000 & 0.298 & 0.76 & $1.01 \mathrm{~K}$ \\
\hline & 1-butanol & 1850 & 0.454 & 0.56 & $0.41 \mathrm{~K}$ & 2050 & 0.454 & 0.87 & $0.46 \mathrm{~K}$ \\
\hline \multirow[t]{3}{*}{ 3-pentanone } & ethanol & 1950 & 0.460 & 0.39 & $0.31 \mathrm{~K}$ & 2700 & 0.352 & 0.54 & $0.55 \mathrm{~K}$ \\
\hline & 2-propanol & 2250 & 0.454 & 0.27 & $0.32 \mathrm{~K}$ & 3000 & 0.304 & 0.84 & $0.40 \mathrm{~K}$ \\
\hline & 1-butanol & 1750 & 0.460 & 0.88 & $0.41 \mathrm{~K}$ & 1950 & 0.454 & 1.44 & $0.54 \mathrm{~K}$ \\
\hline \multicolumn{10}{|l|}{ Ethers } \\
\hline diethyl ether & ethanol & 2100 & 0.304 & 0.48 & $1.42 \%$ & 2450 & 0.280 & 0.58 & $0.55 \%$ \\
\hline \multirow[t]{3}{*}{ dipropyl ether } & ethanol & 1950 & 0.310 & 0.69 & $0.24 \mathrm{~K}$ & 2050 & 0.316 & 0.34 & $0.21 \mathrm{~K}$ \\
\hline & 1-propanol & 1600 & 0.400 & 0.28 & $0.17 \mathrm{~K}$ & 1550 & 0.412 & 0.33 & $0.18 \mathrm{~K}$ \\
\hline & 2-propanol & 1750 & 0.328 & 0.30 & $0.48 \%$ & 1550 & 0.388 & 0.73 & $0.96 \%$ \\
\hline \multirow[t]{3}{*}{ dibutyl ether } & ethanol & 1800 & 0.340 & 0.40 & $0.87 \%$ & 1600 & 0.388 & 0.50 & $1.48 \%$ \\
\hline & 1-butanol & 2050 & 0.286 & 0.70 & $0.37 \mathrm{~K}$ & 2500 & 0.280 & 0.79 & $0.26 \mathrm{~K}$ \\
\hline & 2-butanol & 2550 & 0.286 & 0.62 & $0.28 \mathrm{~K}$ & 2800 & 0.280 & 0.74 & $0.35 \mathrm{~K}$ \\
\hline
\end{tabular}

Based on these results for each functional group, we propose the use of functional group specific association parameters to account for solvation, while using the $\mathrm{N}$ association scheme. This essentially assumes transferability of the parameters and negates the need for parameterisation of each member of the functional group. These functional group parameters correspond to the minimum of the parameter space made up of the equally-weighted parameter spaces of the constituent component mixtures. These parameters are listed in Table 6, and are represented as the "Global" minima in Figures 1 and 2 for the ketones and ethers respectively.

Table 6: Functional group average association parameters to account for solvation with the $N$ scheme

\begin{tabular}{|c|c|c|c|c|}
\hline & $\varepsilon_{\mathrm{K}}^{A B} / k$ & $r_{c}^{A B} / \sigma$ & $\varepsilon_{\mathrm{K}}^{A B} / k$ & $r_{c}^{A B} / \sigma$ \\
\hline & \multicolumn{2}{|c|}{ "2B" Alcohols } & \multicolumn{2}{|c|}{ " 2 C" Alcohols } \\
\hline Ketones & 2550 & 0.334 & 2800 & 0.328 \\
\hline Ethers & 2050 & 0.298 & 2350 & 0.280 \\
\hline
\end{tabular}

At this point, we briefly pause the development of the approach to note the transferability of this proposed methodology to other SAFT variants. While the $\left[\varepsilon^{A B} / k ; r_{c}^{A B} / \sigma\right]$ space is discretised in the SAFT-VR Mie framework here, the $\left[\varepsilon^{A B} / k ; k^{A B}\right]$ space could have been considered if e.g. (s)PCSAFT were to be used instead. The only prerequisite is an accurate non-associating parameter set, like those presented in Table 3, for the SAFT framework of interest. Applying the discretised approach in this way would yield qualitatively similar contour plots to those presented in Figures 1 
and 2, with homologous group solvation parameters determined in much the same way. Thus, by formalising the $\mathrm{N}$ scheme in this way, we hope to provide a systematic tool for use in all model development, and not one that is limited to the SAFT-VR Mie-GV equation of state as presented in this work.

\subsection{Phase Equilibrium Predictions}

The functional group specific solvation parameters of Table 6 are used in conjunction with the SAFT-VR Mie-GV parameters of Table 3 to generate predictions for mixture phase equilibria in this section. We begin by attempting to further narrow the range of accurate parameters by comparing the performance of the parameters determined, considering " $2 \mathrm{~B}$ " alcohols and " $2 \mathrm{C}$ " alcohols, respectively. Figure 3 considers typical results for the ketone and ether sets, where the " $2 \mathrm{~B}$ " alcohol and " $2 \mathrm{C}$ " alcohol parameters yield almost identical results. The plots also serve to re-emphasise the arguments of the previous section, namely that there are negligible differences in the prediction quality of the local and global solvation parameters, despite large differences in their numerical values.
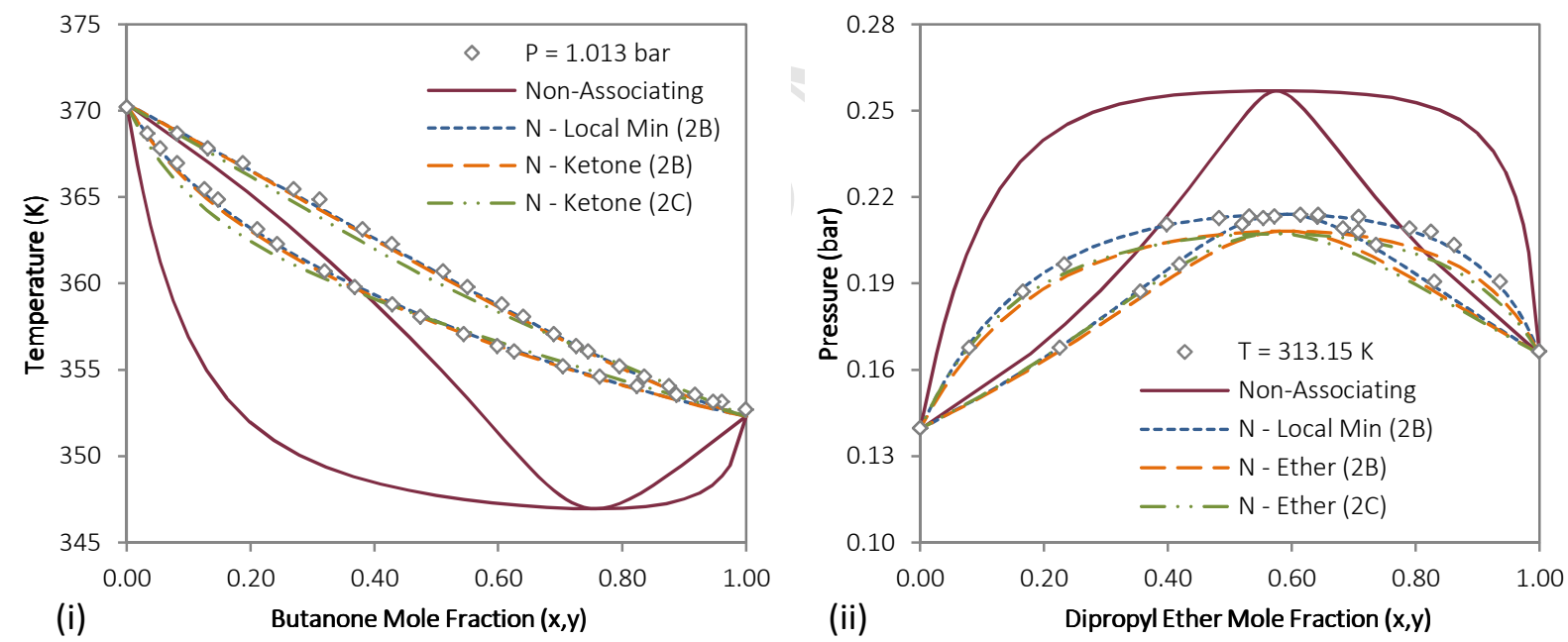

Figure 3: Solvation predictions comparing local and global minimum solvation parameter for (i) ketones: 2-butanone/1-propanol at 1.013 bar [48]; and (ii) ethers: di-n-propyl ether/2-propanol at $313.15 \mathrm{~K}$ [57]. Nonsolvating predictions included for comparison with those of the $N$ scheme.

In order to test the predictive capacity of the $\mathrm{N}$ scheme approach, the solvation parameters need to be applied to systems not considered in the parameterisation procedure. To this end, we consider mixtures with alcohols (Figure 4) larger than those considered in Table 4, systems over extended temperature ranges (Figure 5) as well as the rigorous test of aqueous mixtures (Figure 6). 
The predictions for mixtures with $C_{5}$ alcohols show the same trends as seen in Figure 3 for both homologous groups, with no distinction between the alcohol association schemes. However, the influence of the $\mathrm{N}$ scheme is far more apparent in the 2-pentanone/3-pentanol mixture [62] than in the di-n-propyl ether/1-pentanol mixture [63]. Azeotropic behaviour is falsely predicted in the ketone mixture when solvation is not considered, highlighting the need to account for it explicitly. In the ether system however, only small improvements are made using the $\mathrm{N}$ scheme in the much larger temperature range.
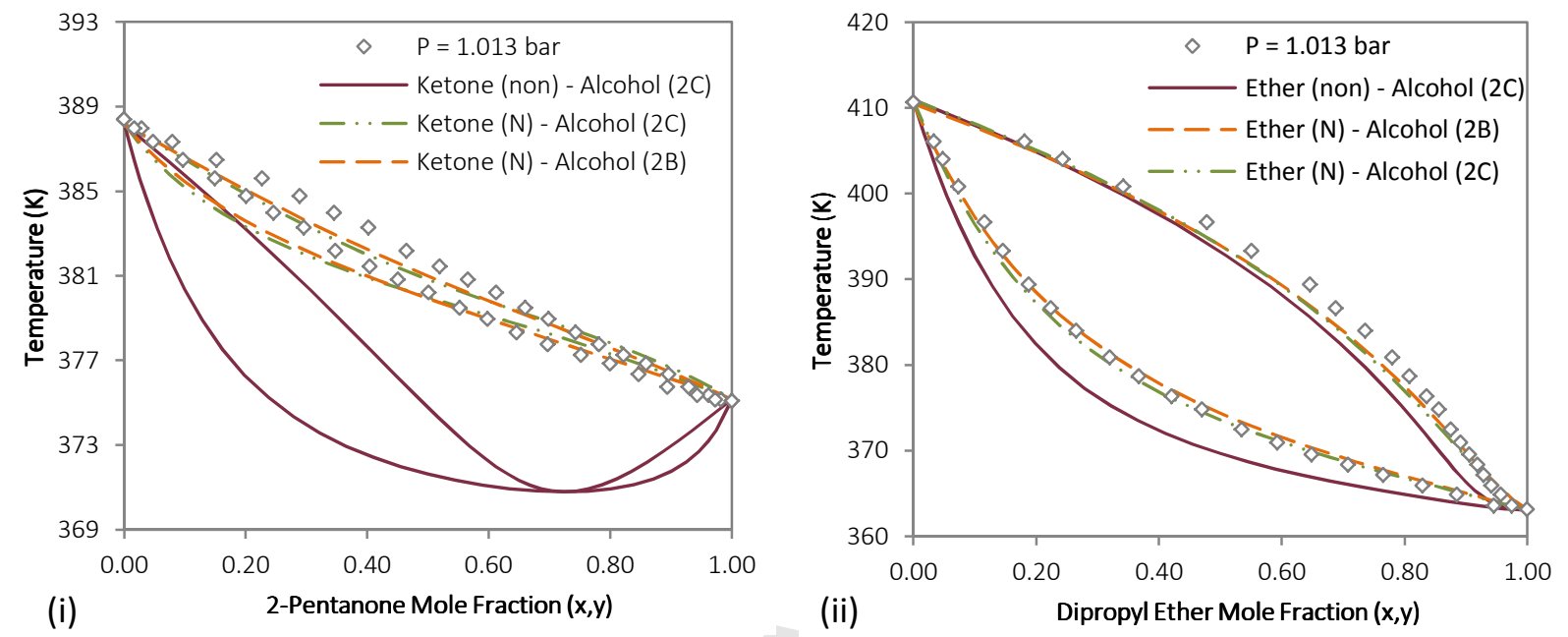

Figure 4: Extrapolation of solvation parameters, considering mixtures with larger alcohols (i) 2-pentanone/3pentanol at 1.013 bar [62]; and (ii) di-n-propyl ether/1-pentanol at 1.013 bar [63]. Non-solvating predictions included for comparison with those of the $N$ scheme.

Considering model predictions for multiple $P$-xy data sets of a given mixture tests for the presence of temperature dependence in the model parameters. In Figure 5, predictions for the 2-butanone/ethanol system at four different temperatures $[64,65]$ are presented. Analysis of the predictions suggests that there is some decrease in prediction quality as the system temperature increases, with AADs in $y$ increasing systematically from 3.70 to 5.85 from the lowest to the highest temperatures considered. The pressure predictions also transition from underpredicting at $298 \mathrm{~K}$ to overpredicting at $383 \mathrm{~K}$ and higher temperatures. The isobaric training data set, with temperature range ( $T \in[347 \mathrm{~K} ; 351 \mathrm{~K}]$ ), exhibited a better fit, reinforcing the suggestion of some degree of temperature dependence. Whether such temperature dependence could be eliminated by incorporating multiple $P$-xy data sets in the regression of solvation parameters is difficult to say at this point as there is limited data available for these solvating systems in the literature. This point will be readdressed as we consider a wider range of functional groups in future work. 


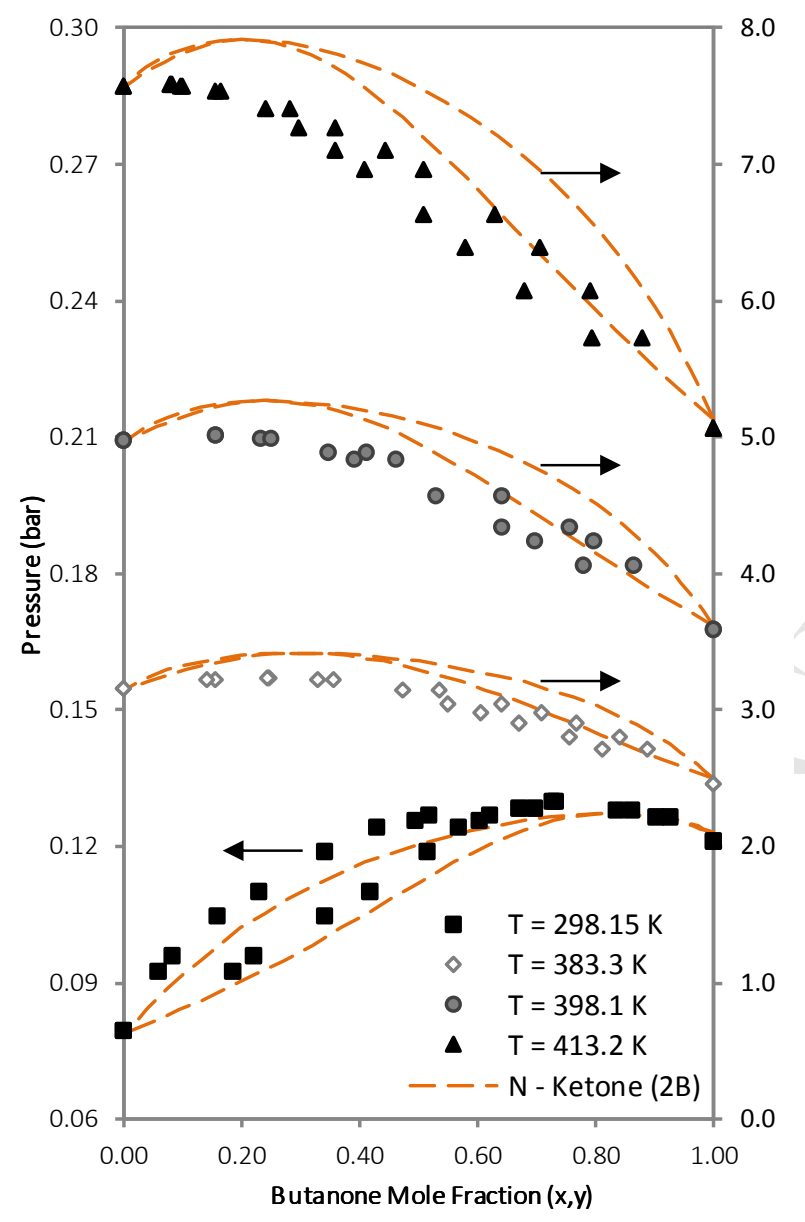

Figure 5: Predictions for the 2-butanone/ethanol system at four different temperatures [64,65]. A subtle trend in prediction quality is evident, suggesting some temperature dependence of the solvation parameters.

Accurate prediction of aqueous organic mixtures is notoriously difficult for equations of state, given the possibility of liquid immiscibility and even vapour-liquid-liquid equilibria. Such behaviour is apparent in the acetone/water [66] and 2-butanone/water [67] systems in Figure 6. In both systems, we find that near complete immiscibility is predicted when the effects of solvation are omitted. The $\mathrm{N}$ scheme approach improves the model predictions for the solubility of water in the organic phase, but the models still struggle to accurately account for ketone solubility in water particularly for the smaller acetone molecule where liquid splitting is still predicted for very low concentrations of acetone. This result is not unfamiliar, as accurate modelling of the aqueous phase is one of the most difficult challenges for thermodynamic models.

In the context of this work however, predictions for the 2-butanone/water allude to the predictive strength of the $\mathrm{N}$ scheme approach and present a notable result. By comparing the predictions from the two sets of solvation parameters, we find that the set based on " $2 \mathrm{C}$ " alcohols offers a notably improved prediction to the set determined with " $2 \mathrm{~B}$ " alcohols. The model still 
struggles in the water-rich region, but behaviour in the ketone rich region is well captured when one uses the solvation parameters generated with " $2 \mathrm{C}$ " alcohols. This corroborates the original findings with the $2 \mathrm{C}$ scheme [68], where phase behaviour of aqueous alcohol mixtures was better predicted using the $2 \mathrm{C}$ scheme. This result is significant as it offers the first notable difference between the parameter sets, and indeed the underlying alcohol parameter sets, in our works so far. As such, notable improvements in model predictions are observed when one accounts for solvation with the $\mathrm{N}$ scheme, albeit that there is still ample room for optimisation in the case of aqueous mixtures.
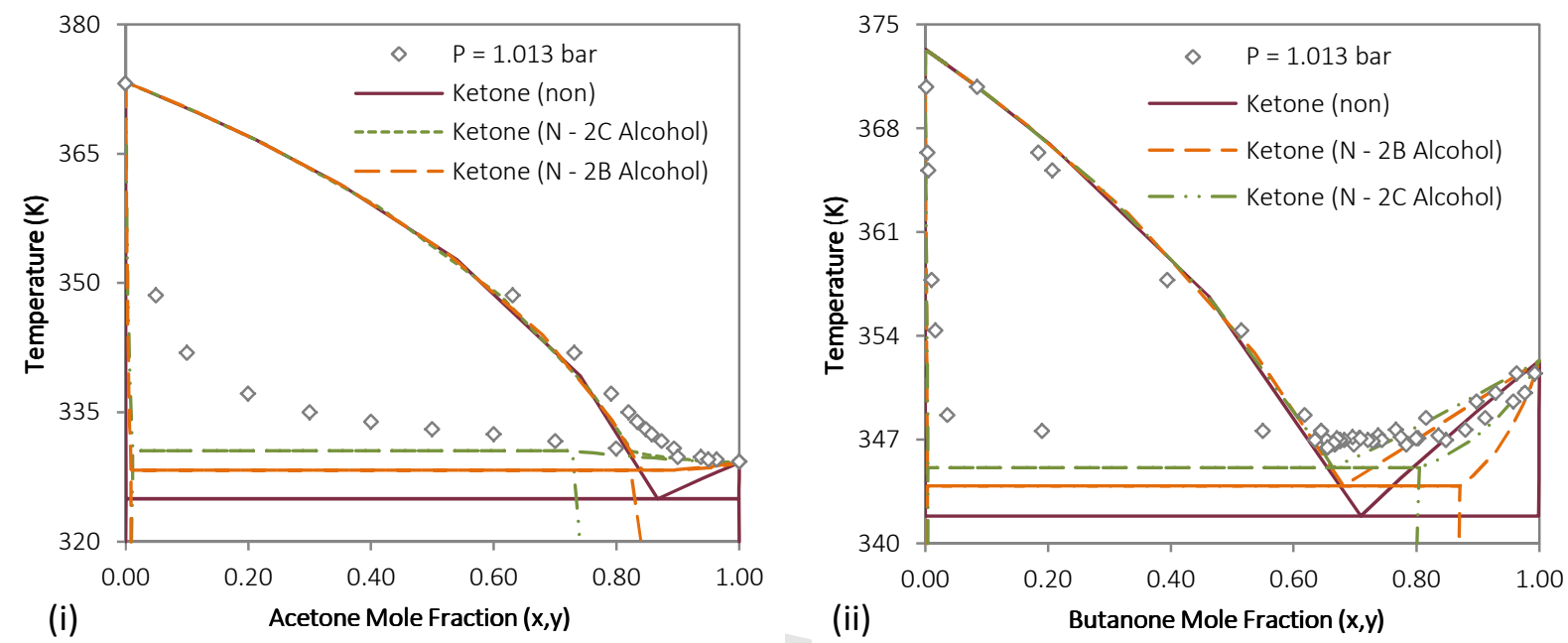

Figure 6: Application of the N scheme approach to solvation in aqueous ketone mixtures: (i) acetone/water at 1.013 bar [66]; and (ii) 2-butanone/water at 1.013 bar [67]. Non-solvating predictions included for comparison with those of the $N$ scheme.

\section{Cross Association in Type I/Type II Mixtures}

The results presented thus far have highlighted the strength of the proposed $\mathrm{N}$ scheme, considering solvation in mixtures with Type III components. However, for the approach to be considered truly predictive, accurate description of cross-association in Type 1/Type II mixtures is vital. A comprehensive treatment of Type I solvation would constitute a body of work on its own, but we believe that a preliminary assessment is necessary to justify further development of this solvation approach. To this end, we limit our discussion to the quintessential Type I/Type II mixture: chloroform/acetone.

\subsection{The P Scheme}

The first step to accounting for Type I solvation is description of the association scheme. Following the same procedure as was used for the $\mathrm{N}$ scheme definition, we begin by considering the chemical structure of chloroform in Table 7, where the three chlorine atoms strongly polarise the 
lone hydrogen atom. This constitutes a proton donor site, or a single "positively" charged association site, which we use as inspiration for the "P scheme" moniker assigned to the resulting association mechanism.

Table 7: P Scheme definition for chloroform

\begin{tabular}{ccc}
\hline Species & Association Scheme & Site Representation \\
\hline & & \\
Chloroform & $\mathbf{P}-\mathrm{Cl}-\mathrm{Cl}$ \\
& $\mathrm{Cl}$ \\
\hline
\end{tabular}

Parameterisation of chloroform in the SAFT-VR Mie-GV framework is conducted in a two-step procedure. The non-associating parameters are determined by discretised regression, following the procedure detailed in our recent work on alcohols [42]. In short, the appropriate dispersion and polar contributions to pure component behaviour are sought by discretising the $\left[\varepsilon / k ; n_{p}\right]$ space. The remaining nonpolar parameters $\left(\sigma, m\right.$ and $\left.\lambda_{r}\right)$ are regressed using an objective function that considers pure component saturation properties [41], as well as compressed liquid speed of sound [69]. This regression procedure yields a matrix of minimised objective function results, each corresponding to a unique parameter set distinguished by discrete values of $\varepsilon / k$ and $n_{p}$. These regressed parameter sets are then used to generate predictions for chloroform/alkane VLE data (here, in mixture with n-hexane [70]), the resulting AADy and \%AADP values for which form matrices in the same $\left[\varepsilon / k ; n_{p}\right]$ space as the minimised objective function matrix. These three matrices are then projected onto contour plots, and the optimal $\left[\varepsilon / k ; n_{p}\right]$ combination, which balances application to pure component and mixture data, is selected.

The second step in the parameterisation is the determination of average solvation parameters for chloroform, by considering chloroform/alcohol VLE data in the same $C_{2}-C_{4}$ alcohol range $[44,53,71,72]$ that was considered for the $\mathrm{N}$ scheme parameterisation. In this preliminary analysis, the discussion is limited to chloroform parameters determined from mixtures where the alcohol is modelled with the $2 \mathrm{~B}$ scheme. The more complex interactions between the $2 \mathrm{C}$ and $\mathrm{P}$ schemes will be investigated in future work. The full regression results are presented in the Supporting Information, with the resulting parameter set presented in Table 8.

Table 8: SAFT-VR Mie-GV parameters for chloroform, accounting for solvation using the $P$ scheme

\begin{tabular}{|c|c|c|c|c|c|c|c|c|c|c|}
\hline & $\begin{array}{c}M_{w} \\
\text { g.mol }{ }^{-1}\end{array}$ & $\begin{array}{l}\sigma \\
\AA\end{array}$ & $m$ & $\begin{array}{c}\varepsilon / k \\
\mathrm{~K}\end{array}$ & $\lambda_{a}$ & $\lambda_{r}$ & $n_{p}$ & $\begin{array}{l}\mu \\
\mathrm{D}\end{array}$ & $\begin{array}{c}\varepsilon^{A B} / k \\
K\end{array}$ & $r_{c}^{A B} / \sigma$ \\
\hline Chloroform & 119.38 & 3.8647 & 1.9368 & 330 & 6 & 13.476 & 3.6 & 1.01 & 1950 & 0.280 \\
\hline
\end{tabular}


These SAFT-VR Mie-GV parameters are evaluated through their application to phase equilibria of chloroform in mixtures with nonpolar (chloroform/n-hexane [70]) and associating (chloroform/methanol [53]) components (Figure 7). The dipole moment of chloroform is small, but comparable to that of the ethers - and as was the case with the ethers, incorporating an explicit polar term is necessary to accurately capture the subtle dipolar effects. As was the case for Type II components, ignoring the effects of solvation results in significant over-prediction of the azeotropic pressure in the chloroform/methanol mixture, since the magnitude of the like interactions is underpredicted. However, the mixture behaviour is accurately accounted for when using the P scheme an important predictive result, given that methanol was not considered in the discretisation procedure for the determination of the solvation parameters. Accurate predictions in these systems are an absolute necessity before we can consider the model's application to cross-association in Type I/Type II systems. The results in Figure 7, combined with the $\mathrm{N}$ scheme results presented earlier, thus provide a solid foundation for further consideration of the complex solvation behaviour in the chloroform/acetone mixture.
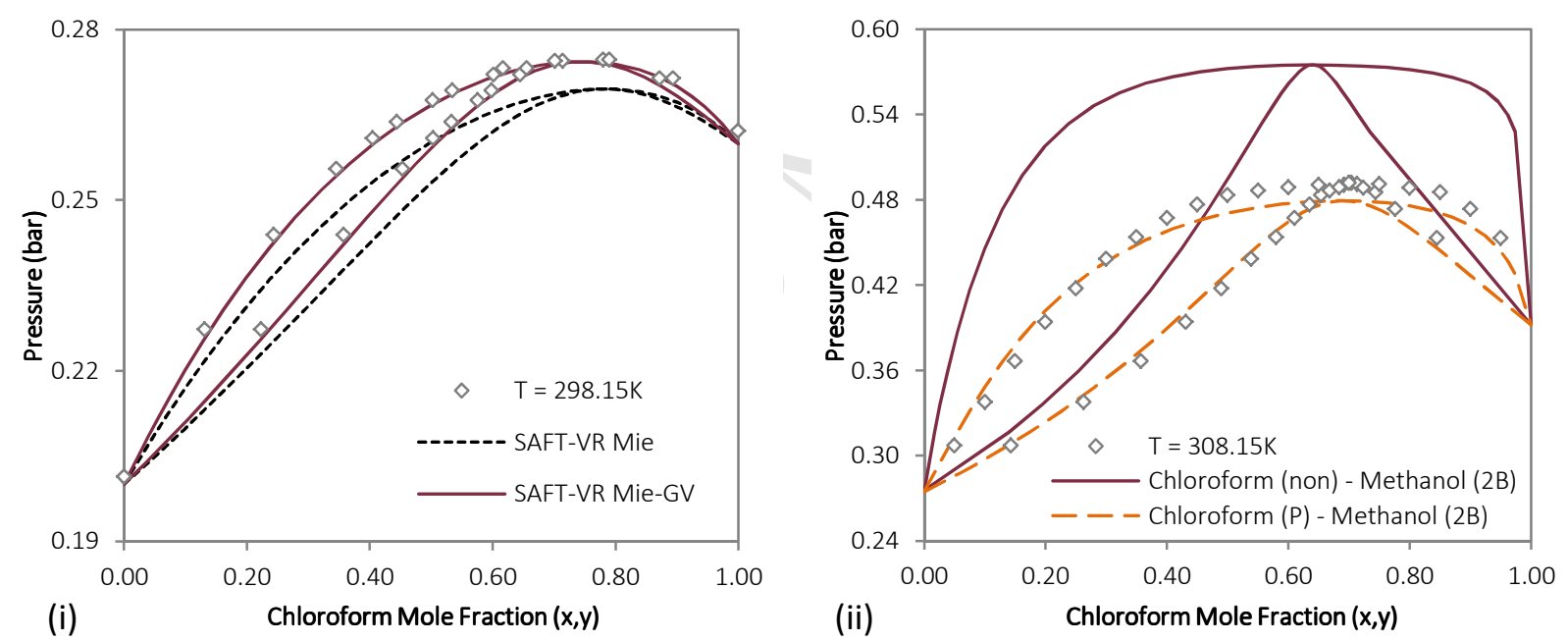

Figure 7: Application of the regressed SAFT-VR Mie-GV parameters for chloroform to mixtures with (i) n-hexane at 298.15K [70], and with (ii) methanol at $308.15 \mathrm{~K}$ [53]. Accurate predictions demonstrate suitability of the explicit polar term in the former, and the new $P$ scheme in the latter.

\subsection{Chloroform/Acetone}

The chloroform/acetone mixture provides the most stringent test of the predictive capacity of the proposed $\mathrm{N}$ and $\mathrm{P}$ schemes, because of the manner in which the solvation parameters are determined. If the association parameters had been fit to chloroform/acetone mixture data, an accurate prediction for the system would be obtained, but such an approach would be entirely correlative, akin to fitting a binary interaction parameter to improve the model fit. However, by 
considering only the cross-association with alcohols in the parameter determination, their application to Type I/Type II solvation is purely predictive and represents a true test of the physical appropriateness of the approach proposed here. The full set of these predictions are presented for the chloroform/acetone mixture [73] in Figure 8.

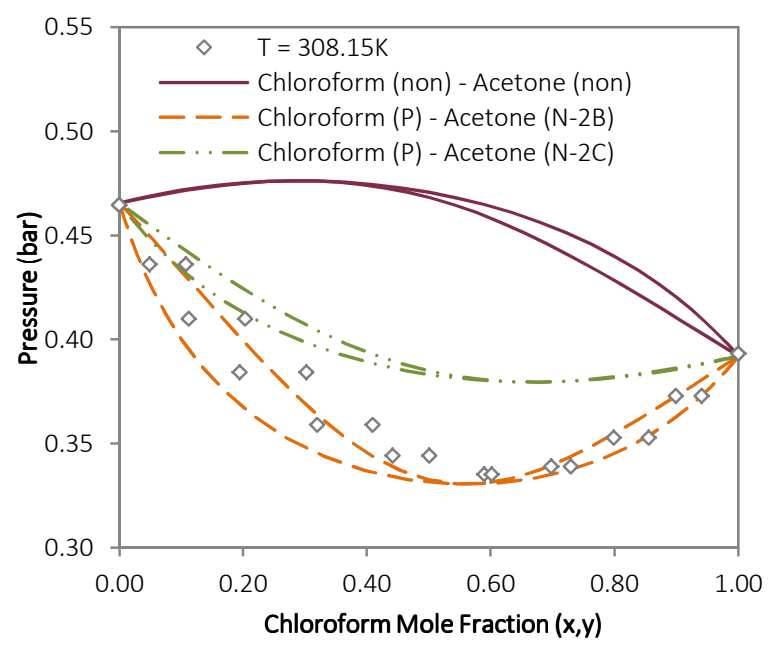

Figure 8: Application of SAFT-VR Mie-GV, considering the proposed $P$ and $N$ schemes, to the phase behaviour of chloroform/acetone at $308.15 \mathrm{~K}$ [73]

By considering both components as non-solvating, the model falsely predicts slight positive deviations from ideality, where substantial negative deviations are witnessed experimentally. While not explicitly shown in Figure 8, identical predictions result if the solvation of only one of the components is considered. This result can be logically predicted if one considers the association mechanisms defined for the $\mathrm{N}$ and $\mathrm{P}$ schemes and the resulting dormancy of the association sites in the mixture when considered this way. However, by explicitly accounting for solvation in both components, notable improvement in the prediction quality is evident. Indeed, there is even good quantitative agreement between the model predictions and the experimental data. The ketone parameters fit using " $2 \mathrm{~B}$ " alcohols yield a better prediction than those using " $2 \mathrm{C}$ " alcohols, although it should be remembered that only " $2 \mathrm{~B}$ " alcohols were considered in determining chloroform's solvation parameters. Therefore, definitive distinctions between the parameterisation approaches cannot be made from these predictions alone, and it is unclear at this stage whether the association scheme of the paired alcohol, used to determine $\mathrm{N}$ and $\mathrm{P}$ scheme parameter sets, has a limiting effect on prediction quality. This should nevertheless not detract from the excellent predictions in evidence. It confirms both the predictive capacity and physical suitability of the proposed $\mathrm{N}$ and $\mathrm{P}$ scheme approaches, which can serve as a solid foundation for further investigation. 


\section{Conclusions}

The aim of this work was to present a formalised approach to account for cross-association within the SAFT framework. Specifically, the approach is physically consistent and entails a generalised methodology that could be applied to any class of solvating component. With a high predictive capacity as priority, our recent works within the SAFT-VR Mie-GV framework $[32,42]$ were used as the foundation for this development. To this end, the Type II behaviour of the ketone and ether homologous series was considered here to demonstrate the generality and transferability of the proposed approach, with brief consideration given to the Type I behaviour of chloroform.

The $\mathrm{N}$ scheme considers the atomic structure of the ketone and ether functional groups and the presence of only negative sites in these components, while similar considerations account for the positive site of chloroform in the $\mathrm{P}$ scheme. These schemes are consistent with our physical understanding of solvation in these components, and the assignment of these schemes ensures that the contribution of association to these components' behaviour is only present in solvating mixtures. Using this basis in the SAFT framework, only two association parameters need to be determined - in this work, the $\varepsilon^{A B} / k$ and $r_{c}^{A B} / \sigma$ parameters of SAFT-VR Mie are considered, although the transferability of the approach to other SAFT frameworks is clear. The proposed approach considers discretisation of the association parameters, without the need for regression, and applies the resulting parameter sets to phase equilibrium data for mixtures with $C_{2}$ to $C_{4}$ alcohols. Projecting the resulting matrices of $A A D$ values onto a contour plot allows for visualisation of the parameter space in each considered mixture. Considering all such contour plots for each ketone and ether, it was found that functional group average parameters generate quantitatively similar predictions to the optimal parameter sets, despite large differences in parameter values.

Using average solvation parameters for different functional groups yields excellent predictions for ketones and ethers with alcohols, even when extrapolating to components not considered in the parameterisation procedure. Good predictions are evident for aqueous mixtures of these components, although accurate description of solubility of the organic component in the aqueous phase still remains elusive. Moreover, application to $P$-xy data over extended temperature ranges suggests some temperature dependence of the parameters. However, the predictive strength of the $\mathrm{N}$ and $\mathrm{P}$ scheme approach is emphasised by the quality of the prediction for the chloroform/acetone mixture, where the notable effects of solvation are well captured. These results will serve as a foundation for further application of the $\mathrm{N}$ and $\mathrm{P}$ schemes to other solvating species in future work. 
Nomenclature

$d$
$H^{v a p}$
$k$
$m$
$M_{W}$
$N_{A}$
$n_{p}$
$P^{s a t}$
$r_{c}^{A B}$
$r_{d}^{A B}$
$u^{l i q}$
$x_{i}$
$X_{A i}$
$\Delta^{A B B j}$
$\varepsilon / k$
$\varepsilon^{A B} / k$
$\kappa^{A B}$
$\lambda_{a}$
$\lambda_{r}$
$\mu$
$\rho^{\text {sat }}$
$\rho_{j}$
$\sigma$

\section{Abbreviations}

$A A D X$

\%AADX

CPA

CR1

$E C R$

FPP

GC-SAFT

$(-) G V$

$(-) J C$

PC-SAFT

SAFT-O

$S A F T_{H R}$ SAFT-VR Mie SPC-SAFT

$S R P$ temperature dependent segment diameter, $\AA$

heat of vaporization

Boltzmann constant, J. $\mathrm{K}^{-1}$

segment number

molecular weight, kg.kmol ${ }^{-1}$

Avogadro's number

number of polar segments

saturated vapour pressure, $\mathrm{kPa}$

range of association, $\AA$

distance between the associating site and its corresponding segment centre, $\AA$

speed of sound in compressed liquid phase, $\mathrm{m} . \mathrm{s}^{-1}$

mole fraction

fraction of molecules $i$ not bonded at site $A$

association strength

dispersion energy parameter, $\mathrm{K}$

association energy parameter, $\mathrm{K}$

Association volume parameter, $\AA^{3}$

Mie attractive range exponent

Mie repulsive range exponent

dipole moment, $\mathrm{D}$

saturated liquid density, $\mathrm{kg} . \mathrm{dm}^{-3}$

number density, $\AA^{-3}$

segment diameter, $\AA$ absolute average deviation, $A A D X=1 / n \sum_{i=1}^{n}\left|X_{i}^{\text {cal }}-X_{i}^{\text {exp }}\right| / X_{i}^{\text {exp }}$

Percentage absolute average deviation, $\% A A D X=100 / n \sum_{i=1}^{n}\left|X_{i}^{\text {cal }}-X_{i}^{\text {exp }}\right| / X_{i}^{\text {exp }}$

Cubic Plus Association

van der Waals one fluid mixing rules

Elliot mixing rules

Fixed Polar Parameter [approach]

group contribution SAFT

(incorporated into the indicated framework) Gross \& Vrabec polar term

(incorporated into the indicated framework) Jog \& Chapman polar term

perturbed chain SAFT

SAFT of the research group of Chapman

SAFT of Huang \& Radosz

SAFT for Mie potentials of variable range

simplified PC-SAFT

Standard Regression Procedure [approach]

\section{Acknowledgements}

The financial assistance of Sasol Technology (Pty) Ltd and the Department of Trade and Industry (DTI) of South Africa through the Technology and Human Resources for Industry Programme (THRIP) towards this research is hereby acknowledged. The financial assistance of the Claude Leon 
Foundation towards this research is hereby acknowledged. Opinions expressed and conclusions arrived at are those of the authors and are not necessarily to be attributed to the sponsors.

\section{References}

[1] S.N. Vinogradov, R.H. Linnell, Hydrogen Bonding, Van Nostrand Reinhold, 1971.

[2] E.K. Müller, K.E. Gubbins, Molecular-based equations of state for associating fluids: A review of SAFT and related approaches, Ind. Eng. Chem. Res. 40 (2001) 2193-2211. doi:10.1021/ie000773w.

[3] G. Jackson, W.G. Chapman, K.E. Gubbins, Phase equilibria of associating fluids: Spherical molecules with multiple bonding sites, Mol. Phys. 65 (1988) 1-31. doi:10.1080/00268978800100821.

[4] W.G. Chapman, K.E. Gubbins, G. Jackson, M. Radosz, SAFT: Equation-of-State Solution Model for Associating Fluids, Fluid Phase Equilib. 52 (1989).

[5] M.S. Wertheim, Fluids with highly directional attractive forces. I. Statistical thermodynamics, J. Stat. Phys. 35 (1984) 19-34. doi:10.1007/BF01017362.

[6] M.S. Wertheim, Fluids with highly directional attractive forces. II. Thermodynamic perturbation theory and integral equations, J. Stat. Phys. 35 (1984) 35-47. doi:10.1007/BF01017363.

[7] M.S. Wertheim, Fluids with highly directional attractive forces. III. Multiple attraction sites, J. Stat. Phys. 42 (1986) 459-476. doi:10.1007/BF01127721.

[8] M.S. Wertheim, Fluids with highly directional attractive forces. IV. Equilibrium polymerization, J. Stat. Phys. 42 (1986) 477-492. doi:10.1007/BF01127722.

[9] M. Kleiner, G. Sadowski, Modeling of polar systems using PCP-SAFT: An approach to account for induced-association interactions, J. Phys. Chem. C. 111 (2007) 15544-15553. doi:10.1021/jp072640v.

[10] S.H. Huang, M. Radosz, Equation of state for small, large, polydisperse and associating molecules, Ind. Eng. Chem. Res. 29 (1990) 2284-2294. doi:10.1021/ie00107a014.

[11] S.H. Huang, M. Radosz, Equation of state for small, large, polydisperse and associating 
molecules: Extension to Fluid Mixtures, Ind. Eng. Chem. Res. 30 (1991) 1994-2005. doi:10.1021/ie00107a014.

[12] N. von Solms, M.L. Michelsen, G.M. Kontogeorgis, Applying Association Theories to Polar Fluids, Ind. Eng. Chem. Res. 43 (2004) 1803-1806. doi:10.1021/ie034243m.

[13] A. Grenner, I. Tsivintzelis, I.G. Economou, C. Panayiotou, G.M. Kontogeorgis, Evaluation of the Nonrandom Hydrogen Bonding (NRHB) Theory and the Simplified Perturbed-Chain-Statistical Associating Fluid Theory (sPC-SAFT). 1. Vapor-Liquid Equilibria, Ind. Eng. Chem. Res. 47 (2008) 5636-5650. doi:10.1021/ie071381t.

[14] G.K. Folas, J. Gabrielsen, M.L. Michelsen, E.H. Stenby, G.M. Kontogeorgis, Application of the Cubic-Plus-Association (CPA) Equation of State to Cross-Associating Systems, Ind. Eng. Chem. Res. 44 (2005) 3823-3833. doi:10.1021/ie048832j.

[15] S.J. Suresht, J.R. Elliott, Multiphase Equilibrium Analysis via a Generalized Equation of State for Associating Mixtures, Ind. Eng. Chem. Res. 31 (1992) 2783-2794. doi:10.1021/ie00012a025.

[16] J.P. Wolbach, S.I. Sandler, Using Molecular Orbital Calculations To Describe the Phase Behavior of Cross-associating Mixtures, Ind. Eng. Chem. Res. 37 (1998) 2917-2928.

[17] S.P. Tan, H. Adidharma, M. Radosz, Recent Advances and Applications of Statistical Associating Fluid Theory, Ind. Eng. Chem. Res. 47 (2008) 8063-8082. doi:10.1021/ie8008764.

[18] M.L. Michelsen, E.M. Hendriks, Physical properties from association models, Fluid Phase Equilib. 180 (2001) 165-174. doi:10.1016/S0378-3812(01)00344-2.

[19] M.L. Michelsen, Robust and Efficient Solution Procedures for Association Models, Ind. Eng. Chem. Res. 45 (2006) 8449-8453. doi:10.1021/ie060029x.

[20] S.P. Tan, H. Adidharma, M. Radosz, Generalized Procedure for Estimating the Fractions of Nonbonded Associating Molecules and Their Derivatives in Thermodynamic Perturbation Theory, Ind. Eng. Chem. Res. 43 (2004) 203-208. doi:10.1021/ie034041q.

[21] G.M. Kontogeorgis, G.K. Folas, Thermodynamic models for industrial applications: from classical and advanced mixing rules to association theories, John Wiley \& Sons, 2009.

[22] O. Ferreira, E.A. Brignole, E.A. Macedo, Modelling of phase equilibria for associating mixtures using an equation of state, J. Chem. Thermodyn. 36 (2004) 1105-1117. 
doi:10.1016/j.jct.2004.07.001.

[23] D. Nguyen-Huynh, A. Falaix, J.-P. Passarello, P. Tobaly, J.-C. de Hemptinne, Predicting VLE of heavy esters and their mixtures using GC-SAFT, Fluid Phase Equilib. 264 (2008) 184-200. doi:10.1016/j.fluid.2007.11.013.

[24] D. Nguyen-Huynh, J.-P. Passarello, J.-C. de Hemptinne, P. Tobaly, Extension of polar GC-SAFT to systems containing some oxygenated compounds: Application to ethers, aldehydes and ketones, Fluid Phase Equilib. 307 (2011) 142-159. doi:10.1016/j.fluid.2011.04.009.

[25] M.L. Corazza, W.A. Fouad, W.G. Chapman, Application of molecular modeling to the vaporliquid equilibrium of alkyl esters (biodiesel) and alcohols systems, Fuel. 161 (2015) 34-42. doi:10.1016/j.fuel.2015.08.003.

[26] M.L. Corazza, W.A. Fouad, W.G. Chapman, PC-SAFT predictions of VLE and LLE of systems related to biodiesel production, Fluid Phase Equilib. 416 (2016) 130-137. doi:10.1016/j.fluid.2015.09.044.

[27] M. Sadeqzadeh, V. Papaioannou, S. Dufal, C.S. Adjiman, G. Jackson, A. Galindo, The development of unlike induced association-site models to study the phase behaviour of aqueous mixtures comprising acetone, alkanes and alkyl carboxylic acids with the SAFT-g Mie group contribution methodology, Fluid Phase Equilib. 407 (2016) 38-57. doi:10.1016/j.fluid.2015.07.04.

[28] P.K. Jog, S.G. Sauer, J. Blaesing, W.G. Chapman, Application of Dipolar Chain Theory to the Phase Behavior of Polar Fluids and Mixtures, Ind. Eng. Chem. Res. 40 (2001) 4641-4648. doi:10.1021/ie010264+.

[29] F. Tumakaka, G. Sadowski, Application of the Perturbed-Chain SAFT equation of state to polar systems, Fluid Phase Equilib. 217 (2004) 233-239. doi:10.1016/j.fluid.2002.12.002.

[30] J. Gross, J. Vrabec, An equation-of-state contribution for polar components: Dipolar molecules, AIChE J. 52 (2006) 1194-1204. doi:10.1002/aic.10683.

[31] A.J. De Villiers, C.E. Schwarz, A.J. Burger, Improving vapour-liquid-equilibria predictions for mixtures with non-associating polar components using SPC-SAFT extended with two dipolar terms, Fluid Phase Equilib. 305 (2011) 174-184. doi:10.1016/j.fluid.2011.03.025.

[32] J.T. Cripwell, C.E. Schwarz, A.J. Burger, SAFT-VR-Mie with an incorporated polar term for accurate holistic prediction of the thermodynamic properties of polar components, Fluid 
Phase Equilib. 455 (2018) 24-42. doi:10.1016/j.fluid.2017.09.027.

[33] P.K. Jog, W.G. Chapman, Application of Wertheim's thermodynamic perturbation theory to dipolar hard sphere chains, Mol. Phys. 97 (1999) 307-319.

[34] A. Dominik, W.G. Chapman, M. Kleiner, G. Sadowski, Modeling of polar systems with the perturbed-chain SAFT equation of state. Investigation of the performance of two polar terms, Ind. Eng. Chem. Res. 44 (2005) 6928-6938. doi:10.1021/ie050071c.

[35] F.J. Kruger, FTIR measurement of monomer fractions in dilute alcohol-acetone systems for the evaluation of the SPC-SAFT EoS, Stellenbosch University, 2013.

[36] T. Lafitte, A. Apostolakou, C. Avendaño, A. Galindo, C.S. Adjiman, E.A. Müller, G. Jackson, Accurate statistical associating fluid theory for chain molecules formed from Mie segments, J. Chem. Phys. 139 (2013). doi:10.1063/1.4819786.

[37] R.G. de Azevedo, J. Szydlowski, P.F. Pires, J.M.S.S. Esperança, H.J.R. Guedes, L.P.N. Rebelo, A novel non-intrusive microcell for sound-speed measurements in liquids. Speed of sound and thermodynamic properties of 2-propanone at pressures up to $160 \mathrm{MPa}$, J. Chem. Thermodyn. 36 (2004) 211-222. doi:10.1016/j.jct.2003.12.001.

[38] M.A. Varfolomeev, K. V Zaitseva, I.T. Rakipov, B.N. Solomonov, W. Marczak, Speed of Sound, Density, and Related Thermodynamic Excess Properties of Binary Mixtures of Butan-2-one with C1-C4 n- Alkanols and Chloroform, J. Chem. Eng. Data. 59 (2014) 4118-4132. doi:10.1021/je5007604.

[39] A. Cobos, F. Hevia, J.A. González, I.G. De, L. Fuente, C.A. Tristán, Thermodynamics of amide + ketone mixtures. 1. Volumetric, speed of sound and refractive index data for $\mathrm{N}, \mathrm{N}-$ dimethylformamide + 2-alkanone systems at several temperatures, J. Chem. Thermodyn. 98 (2016) 21-32. doi:10.1016/j.jct.2016.02.016.

[40] J.A. González, I. Alonso, Thermodynamics of (ketone+amine) mixtures. Part VI. Volumetric and speed of sound data at $(293.15,298.15$, and 303.15)K for (2-heptanone+dipropylamine, +dibutylamine, or +triethylamine) systems, J. Chem. Thermodyn. 43 (2011) 1506-1514. doi:10.1016/j.jct.2011.05.003.

[41] Design Institute for Physical Properties of the American Institute of Chemical Engineers, DIPPR $^{\circledR} 801$ Database, (n.d.). https://www.aiche.org/dippr/eventsproducts/\%0A801-database.

[42] J.T. Cripwell, S.A.M. Smith, C.E. Schwarz, A.J. Burger, SAFT-VR Mie: Application to phase 
equilibria of alcohols in mixtures with n-alkanes and water, Ind. Eng. Chem. Res. 57 (2018) 9693-9706. doi:10.1021/acs.iecr.8b01042.

[43] A.R. Gordon, W.G. Hines, Liquid-Vapour Equilibrium for the System Ethanol-Acetone, Can. J. Res. 24b (1946) 254-262. doi:10.1139/cjr46b-034.

[44] J. Gmehling, U. Onken, Dechema Chemistry Data Series: Vapour-Liquid Equilibrium Data Collection, DECHEMA, Frankfurt, Germany, 2007.

[45] N. Gultekin, Vapor-Liquid Equilibria for Binary and Ternary Systems Composed of Acetone, 2Propanol, and 1-Propanol, J. Chem. Eng. Data. 34 (1989) 168-171. doi:10.1021/je00056a006.

[46] D. Ling, M. Van Winkle, Properties of Binary Mixtures as Function of Composition, Ind. Eng. Chem. 3 (1958) 88-95. doi:10.1021/i460003a018.

[47] P. Reddy, J.D. Raal, D. Ramjugernath, A novel dynamic recirculating apparatus for vapourliquid equilibrium measurements at moderate pressures and temperatures, Fluid Phase Equilib. 358 (2013) 121-130. doi:10.1016/j.fluid.2013.07.044.

[48] N.F. Martínez, E. Lladosa, C. Burguet, J.B. Montón, Isobaric vapour-liquid equilibria for binary systems of 2-butanone with ethanol, 1-propanol, and 2-propanol at 20 and $101.3 \mathrm{kPa}$, Fluid Phase Equilib. 270 (2008) 62-68. doi:10.1016/j.fluid.2008.06.004.

[49] H. Tanaka, T. Muramatsu, M. Kato, Isobaric Vapor-Liquid Equilibria for Three Binary Systems of 2-Butanone with 3-Methyl-1-butanol, 1-Butanol, or 2-Butanol, J. Chem. Eng. Data. 37 (1992) 164-166. doi:10.1021/je00006a007.

[50] L. Hellwig, M. van Winkle, Vapor-Liquid Equilibria for Ethyl Alcohol Binary Systems, Ind. Eng. Chem. Res. 45 (1953) 624-629. doi:10.1021/ie50519a044.

[51] L. Ballard, M. van Winkle, Vapor-Liquid Equilibria at 760-Mm. Pressure 2-Propanol-Methyl Propyl Ketone and 2-Propanol-Methyl Isobutyl Ketone Systems, Ind. Eng. Chem. 45 (1953) 1803-1804. doi:10.1021/ie50524a053.

[52] M. Do Seo, Y. Jo Kim, J. Sung Lim, J. Won Kang, Measurement and correlation of the isobaric vapor-liquid equilibrium for mixtures of alcohol+ketone systems at atmospheric pressure, Korean J. Chem. Eng. 29 (2012) 103-110. doi:10.1007/s11814-011-0147-9.

[53] J. Gmehling, U. Onken, Dechema Chemistry Data Series: Vapour Liquid Equilibrium Data Collection, DECHEMA, Frankfurt, Germany, 1977. 
[54] T.-Y. Wen, M. Tang, Y.-P. Chen, Vapor-liquid equilibria of the binary mixtures 2-butanone + tpentanol, t-pentanol + butyl acetate and 2-propanol + diethyl ketone at $101.3 \mathrm{kPa}$, Fluid Phase Equilib. 163 (1999) 99-108. doi:10.1016/S0378-3812(99)00206-X.

[55] A. Tamir, J. Wisniak, Vapor-Liquid Equilibria in the Ternary Systems tert -Butyl Alcohol-Diethyl Ketone-Methyl Isobutyl Ketone and Diethyl Ketone-Methyl Isobutyl Ketone-n-Butyl Alcohol and Their Binaries, J. Chem. Eng. Data. 23 (1978). doi:10.1021/je60079a015.

[56] E. Lladosa, J.B. Montón, M.C. Burguet, R. Muñoz, Isobaric vapor-liquid equilibria for the binary systems 1-propyl alcohol + dipropyl ether and 1-butyl alcohol + dibutyl ether at 20 and 101.3 kPa, Fluid Phase Equilib. 247 (2006) 47-53. doi:10.1016/j.fluid.2006.06.017.

[57] R. Garriga, F. Sánchez, P. Pérez, M. Gracia, Isothermal vapour-liquid equilibrium at eight temperatures and excess functions at $298.15 \mathrm{~K}$ of di-n-propylether with 1-propanol or 2propanol, Fluid Phase Equilib. 138 (1997) 131-144. doi:10.1016/S0378-3812(97)00173-8.

[58] K.-J. Han, I.-C. Hwang, S.-J. Park, I.-H. Park, Isothermal Vapor-Liquid Equilibrium at 333.15 K, Density, and Refractive Index at $298.15 \mathrm{~K}$ for the Ternary Mixture of Dibutyl Ether + Ethanol + Benzene and Binary Subsystems, J. Chem. Eng. Data. 52 (2007) 1018-1024. doi:10.1021/je600578u.

[59] G. Benito, A. Cart, M. Angel Urueiia, Vapor-Liquid Equilibria for the Mixtures Ether + 2Butanol and + Propyl Acetate at 101.3 kPa, J. Chem. Eng. Data. (1994) 249-250. doi:10.1021/je00014a013.

[60] G.N.I. Clark, A.J. Haslam, A. Galindo, G. Jackson, Developing optimal Wertheim-like models of water for use in Statistical Associating Fluid Theory (SAFT) and related approaches, Mol. Phys. 104 (2006) 3561-3581. doi:10.1080/00268970601081475.

[61] S. Dufal, T. Lafitte, A.J. Haslam, A. Galindo, G.N.I. Clark, C. Vega, G. Jackson, The A in SAFT: developing the contribution of association to the Helmholtz free energy within a Wertheim TPT1 treatment of generic Mie fluids, Mol. Phys. 113 (2015) 948-984. doi:10.1080/00268976.2015.1029027.

[62] A. Aucejo, C. Gabaldó, S. Loras, P. Marzal, M. Sanchotello, Phase Equilibria in the Binary and Ternary Systems Composed of Diethyl Ketone, 2-Pentanone, and 3-Pentanol at $101.3 \mathrm{kPa}$, J. Chem. Eng. Data. 48 (2003) 1128-1131. doi:10.1021/je025651k.

[63] E. Lladosa, J.B. Montón, M.C. Burguet, R. Muñoz, Vapor-liquid equilibria in the ternary 
system dipropyl ether + 1-propanol + 1-pentanol and the binary systems dipropyl ether + 1pentanol, 1-propanol + 1-pentanol at 101.3 kPa, Fluid Phase Equilib. 247 (2006) 175-181. doi:10.1016/j.fluid.2006.07.003.

[64] T. Ohta, J. Koyabu, I. Nagata, Vapor-Liquid Equilibria for the Ternary Ethanol-2-ButanoneBenzene System at 298.15 K, Fluid Phase Equilib. 7 (1981) 63-73.

[65] C. Narasigadu, P. Naidoo, C. Coquelet, D. Richon, D. Ramjugernath, Isothermal Vapor-Liquid Equilibrium Data for the Butan-2-one + Methanol or Ethanol Systems Using a Static-Analytic Microcell, J. Chem. Eng. Data. 58 (2013) 1280-1287. doi:10.1021/je400065j.

[66] M. Kato, T. Sato, H. Konishi, M. Hirata, New method for measuring ternary vapor-liquid equilibria, J. Chem. Eng. Japan. 4 (1971) 311-318. doi:10.1252/jcej.4.311.

[67] D.F. Othmer, M.M. Chudgar, S.L. Levy, Binary and Ternary Systems of Acetone, Methyl Ethyl Ketone, and Water, Ind. Eng. Chem. 44 (1952) 1872-1881. doi:10.1021/ie50512a042.

[68] A.J. De Villiers, C.E. Schwarz, A.J. Burger, New Association Scheme for 1-Alcohols in Alcohol/Water Mixtures with sPC-SAFT: The 2C Association Scheme, Ind. Eng. Chem. Res. 50 (2011) 8711-8725. doi:10.1021/ie200521k.

[69] R.T. Lagemann, D.R. McMillan, W.E. Woolf, Temperature Variation of Ultrasonic Velocity in Liquids, J. Chem. Phys. 17 (1949) 369-373. doi:10.1063/1.1747261.

[70] T.G. Bissell, A.G. Williamson, Vapour pressures and excess Gibbs energies of $n$-hexane and of n-heptane + carbon tetrachloride and + chloroform at 298.15 K, J. Chem. Thermodyn. 7 (1975) 131-136. doi:10.1016/0021-9614(75)90260-8.

[71] I. Nagata, Vapor-Liquid Equilibria for the Ternary System 2-Propanol-Chloroform-Benzene at 50 C, J. Chem. Eng. Data. 30 (1980) 80-82. http://pubs.acs.org/doi/pdf/10.1021/je00039a027 (accessed November 30, 2017).

[72] G.-H. Chen, Q. Wang, Z.-M. Ma, X.-H. Yan, S.-J. Han, Phase Equilibria at Superatmospheric Pressures for Systems Containing Halohydrocarbon, Aromatic Hydrocarbon, and Alcohol, J. Chem. Eng. Data. 40 (1995) 361-366.

[73] R.P. Danner, M.A. Gess, A data base standard for the evaluation of vapor-liquid-equilibrium models, Fluid Phase Equilib. 56 (1990) 285-301. doi:10.1016/0378-3812(90)85109-N. 